الاورية العلمية لكلية الفنون الجميلة ـ جامعة الإسكندرية

SJPA Scientific Journal of the Faculty of Fine Arts Alexandria University

\title{
الإدراك الذهنى للصورة البصريّة فى تصميم الحيّزات الداخليّة المعاصرة
}

\author{
د.زينب لطفى عبد الحكيم خليفة'
}

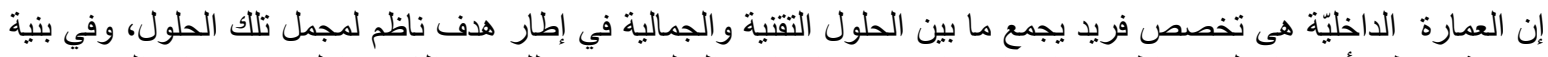

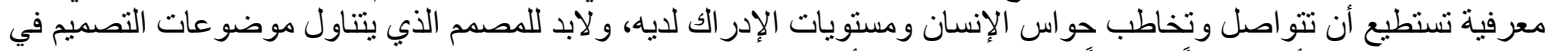

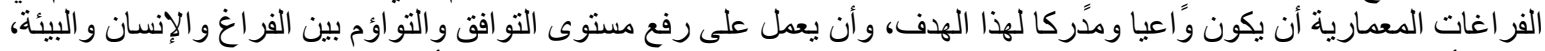

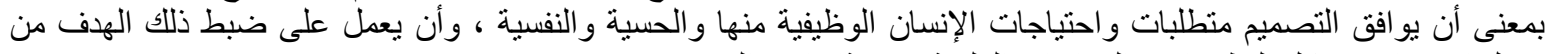

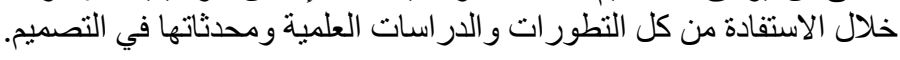

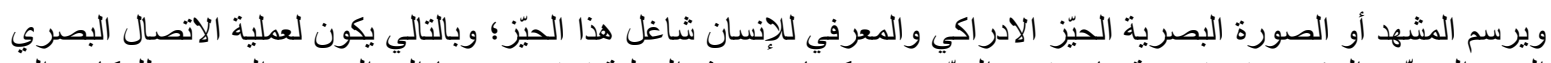

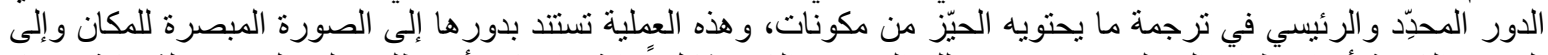

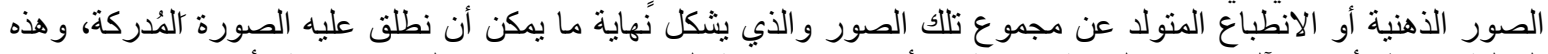

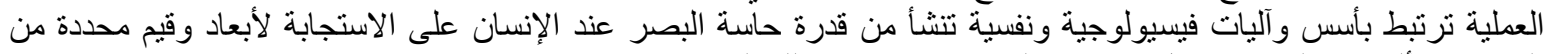

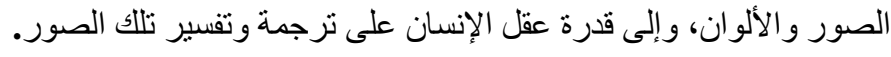

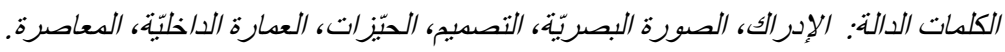

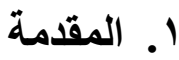

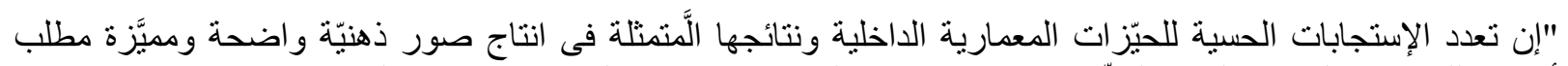

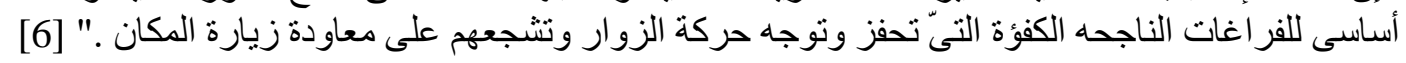

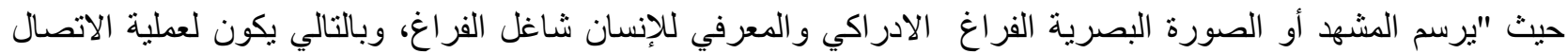

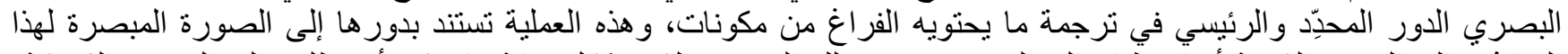

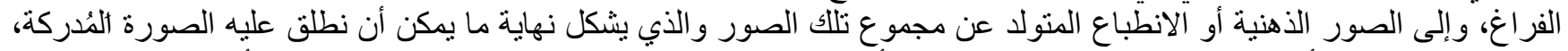

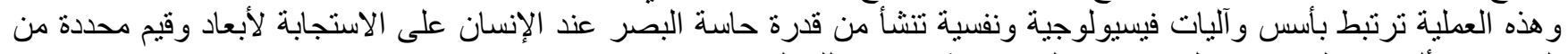

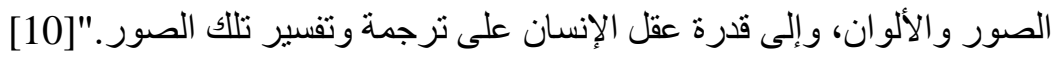

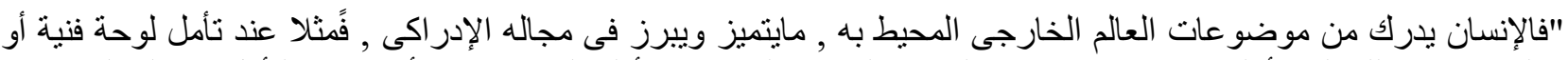

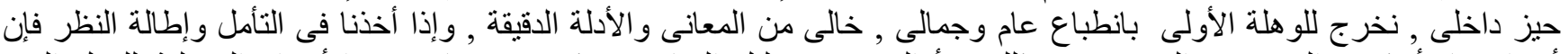

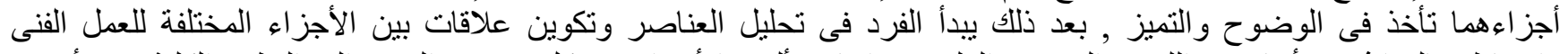

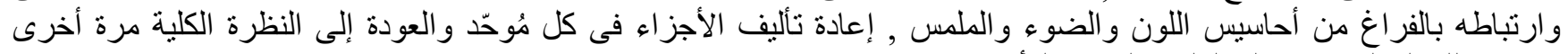

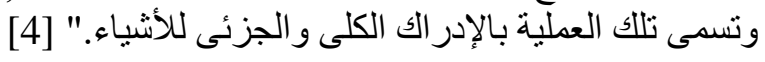


"ومن هذا المنطلق يستطيع المصمم تنظيم هذا الانتقال البصري ضمن سياق الهدف الذي ينشده في الحيّز الداخلي فهو

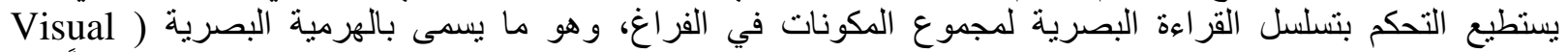

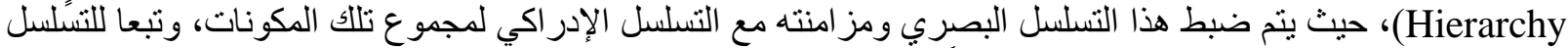

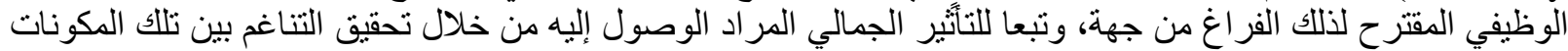

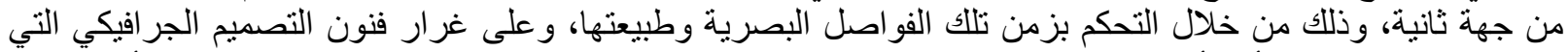

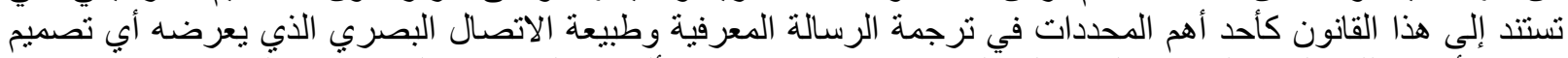

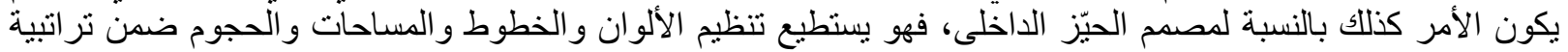
بصرية وزمنية تحافظ على قيم التناغم والجمال بينها، وتنسجم في الوقت ذاته مع النسان النسق الوظيفي ومحددات نشاط الإنسان

داخل الفر اغ ، ويتم بالتالي ضبط الهدف المنمثل في طبيعة البنية الإدر اكية المر اد الوصول إليها عند ذللك الإنسان." [10]

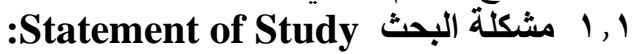

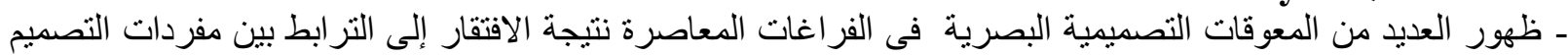

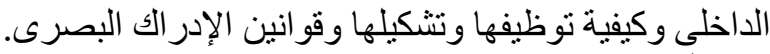

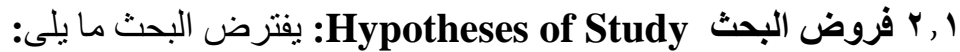

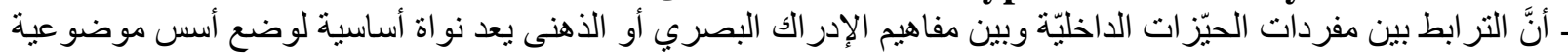

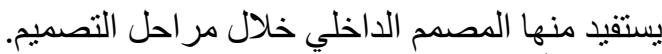
ـ أنَّ الإدر الك الذهنى للصئورة البصرية تؤثر إيجابيا على معالجة بعض المشاكل التصميمية للحيز الداخلي.

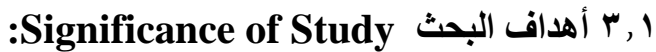
ـ التعرف على المؤثرات التى يتحقق من خلالها الإدر الك و الاستيعاب و اعتمادها كمحدد تصميمى أثناء عملية وضع الفكرة التصميمية. - محاولة التوصل إلى مؤشرات الحيّز ات الداخلية التى تمنلك صورة ذهنيّة واضحة ومميزة بسهل إسترجاعها من خلال

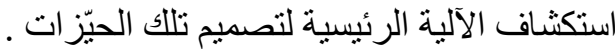

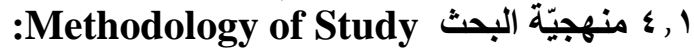

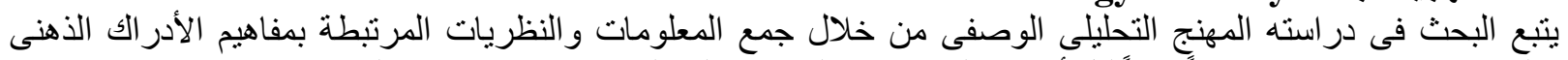

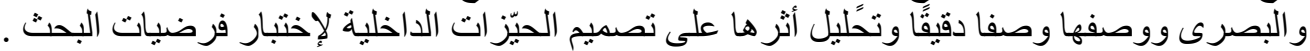

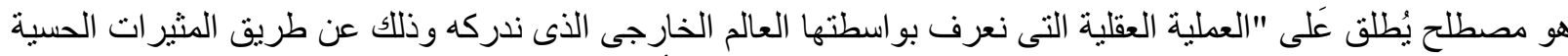

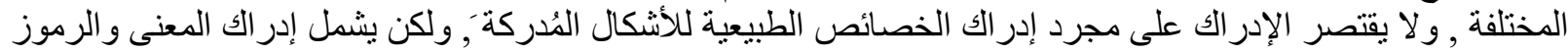
التى لها دلالة بالنسبة للمثير ات الإدرات الحسية فالإدر الك هو عملية حسية ذهنية." [17]

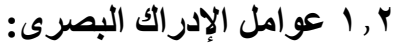

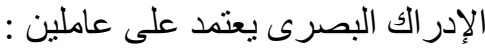

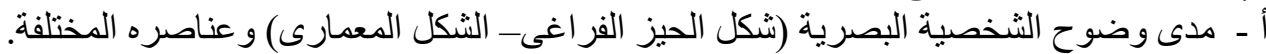

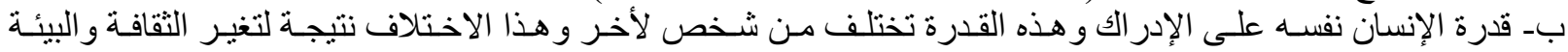

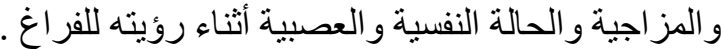

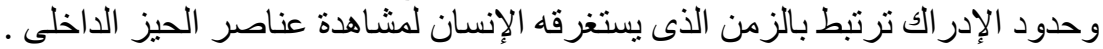

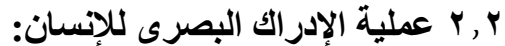

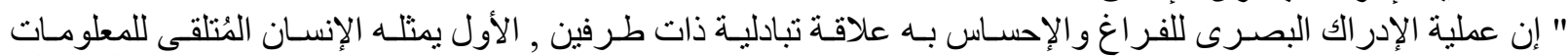

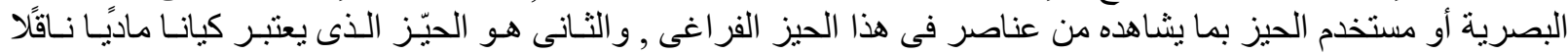

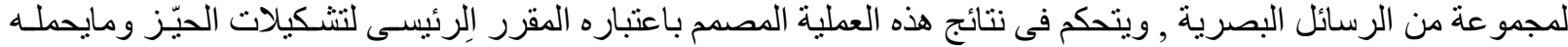

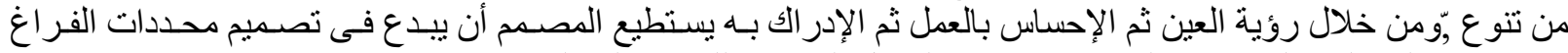

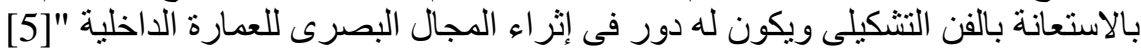

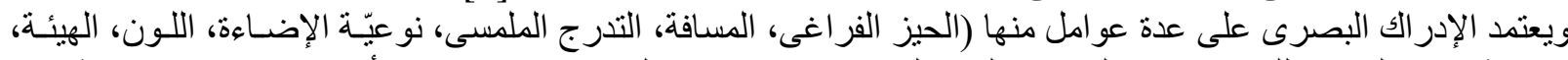

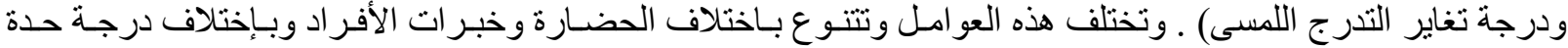

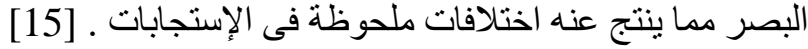




\section{SJFA Scientific Journal of the Faculty of Fine Arts Alexandria University}

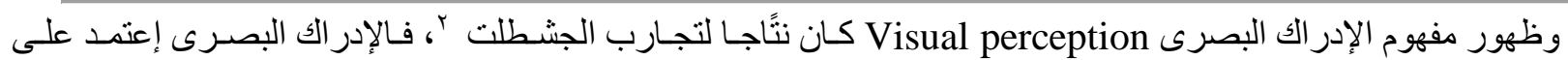

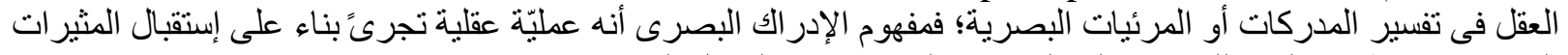

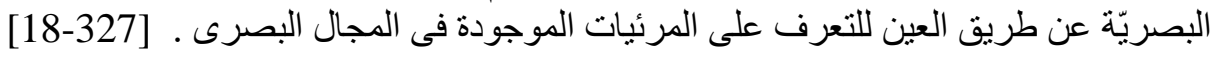

\section{r. - م الإستجابة البصرية}

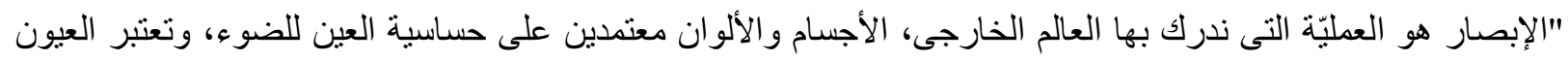

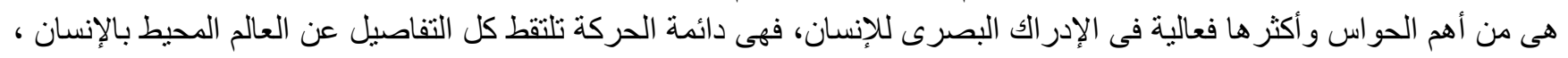

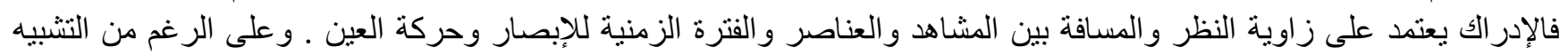

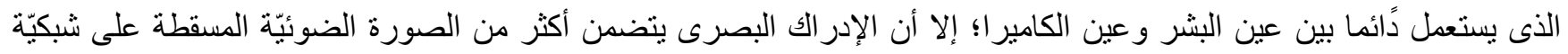

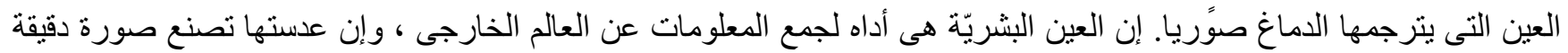

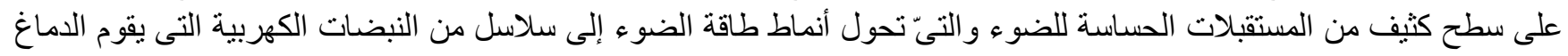

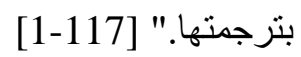

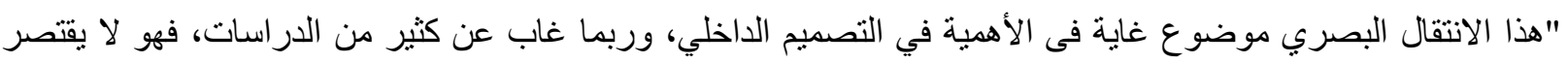

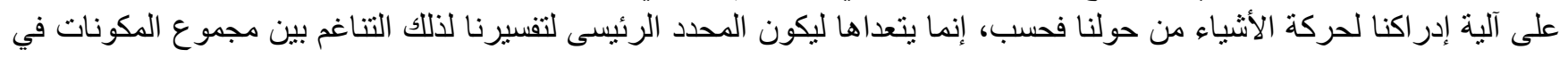

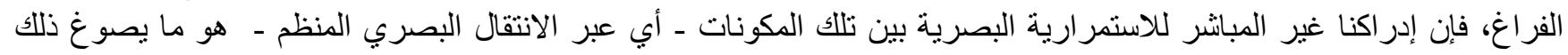

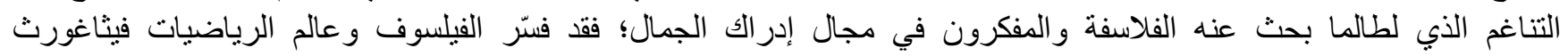

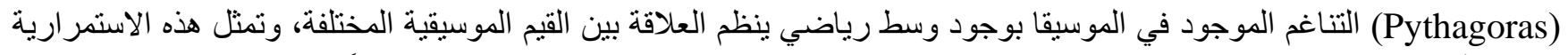

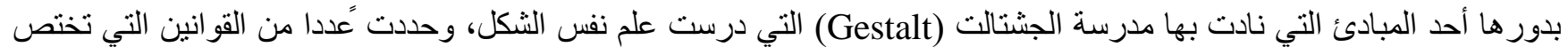

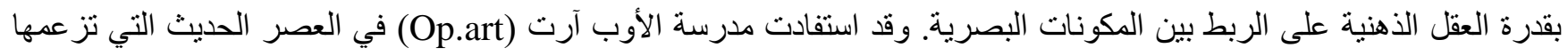

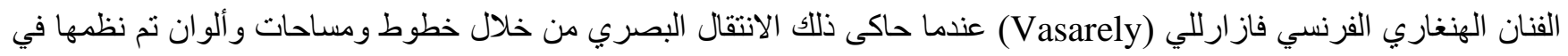

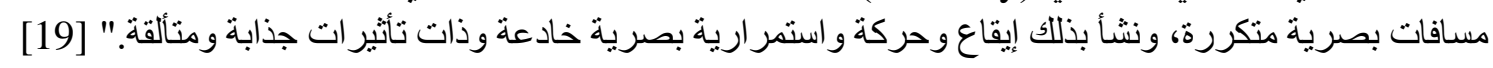

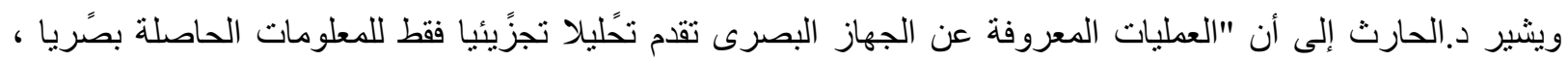

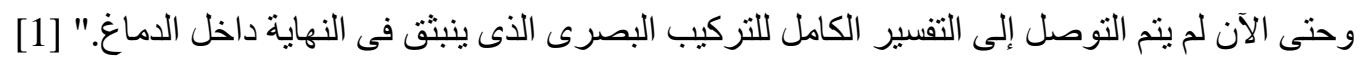

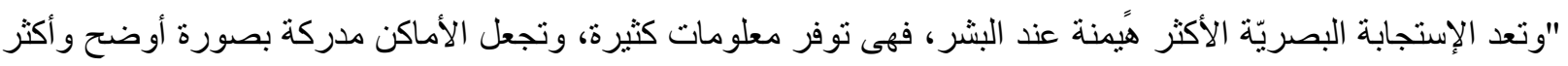

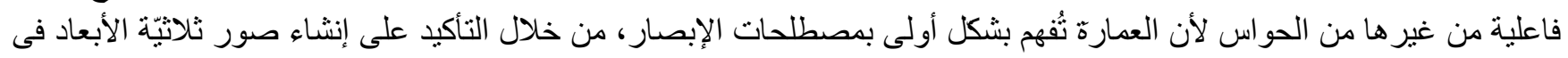

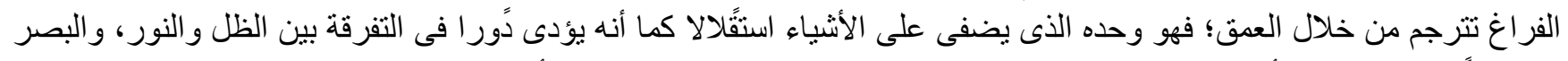

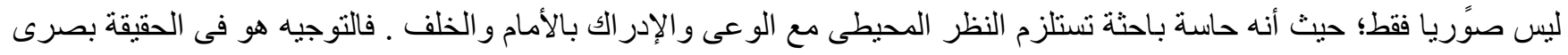

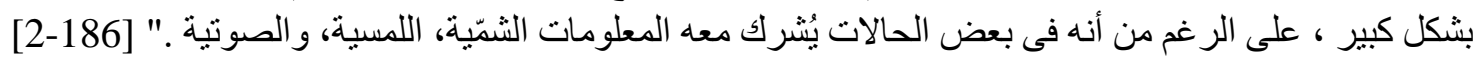

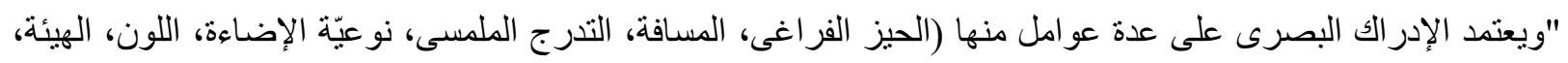

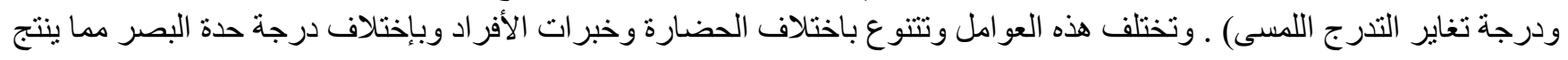

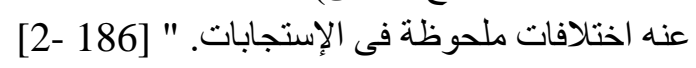

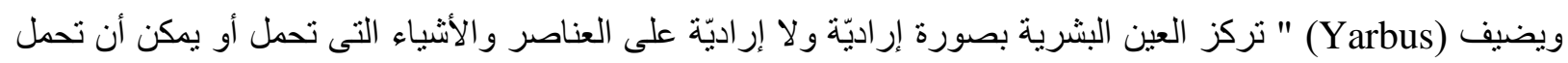

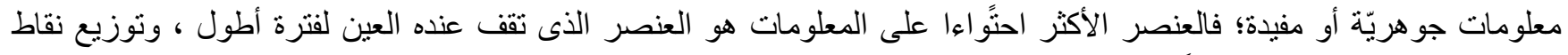

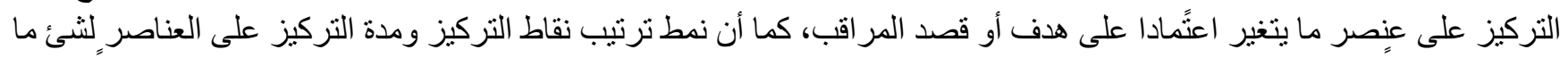

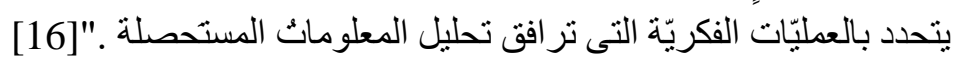

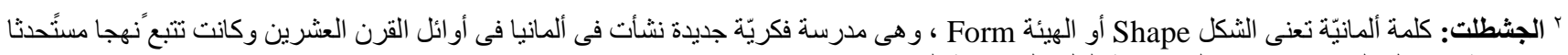
IP a g e r

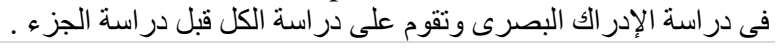


Z. L. Abd Elhakeem, Mental Perception of Visual Image in Designing Contemporary Interior Spaces ;

Vol. 8, R. 2020, Issue No. 1.

كما تشير أطروحات كل من (Malnar \& Vodvarka) إلى أن "ذاكرتنا للأشكال الحرّة المعقدة جيّّة فى الذاكرة قصبرة

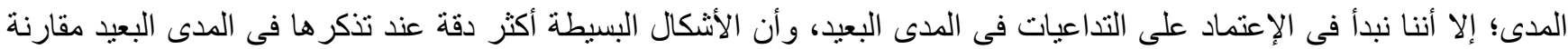

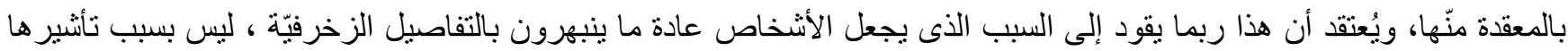

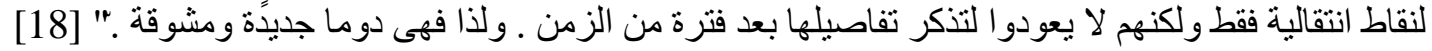

\section{ع. التكوين الإدراكى البصرى للإنسان داخل الحيّز}

"الإدر الك البصرى هو الوسيلة الرئيسية لفهم خصائص التشكيل البصرى للثكل المعمارى ولعناصر الحيز الداخلى وللأعمال

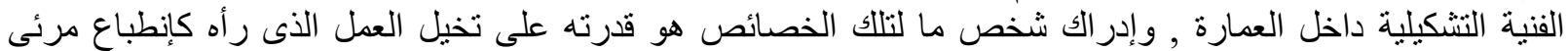

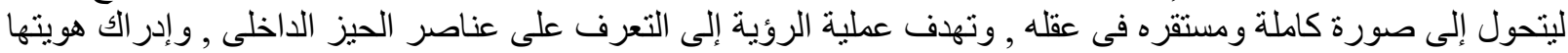

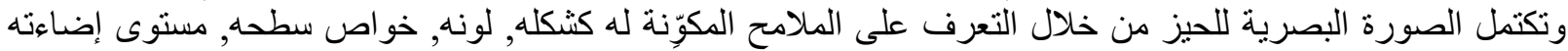

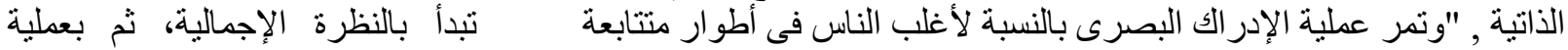

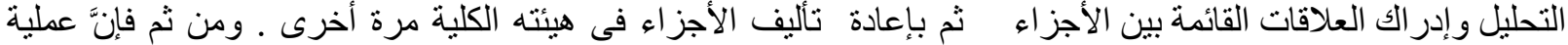

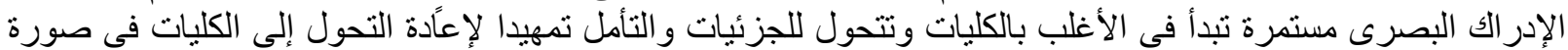

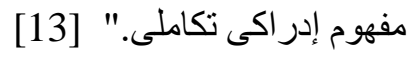

•. الإدراك السياقى والصورة الذهنية

ركزت در اسات (Hall) على الحيّز الداخلى وكيفيّة اختبار الأشخاص له ، وكيفية خلقهم نماذج (models) للحيزات الفر اغية

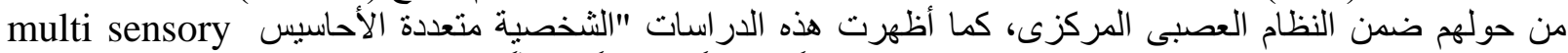
"character

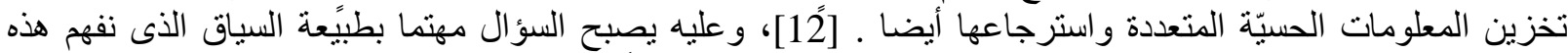

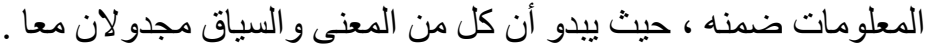

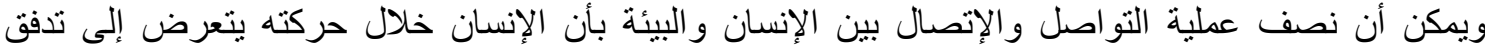

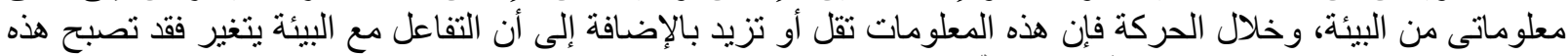

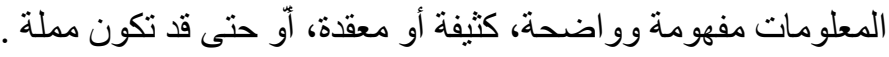

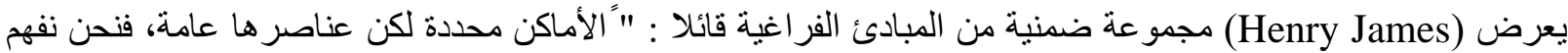

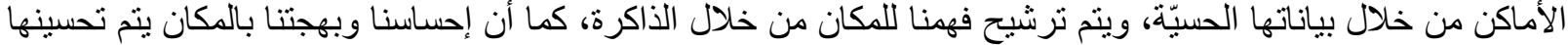

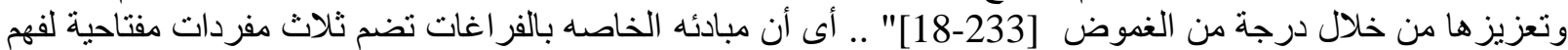

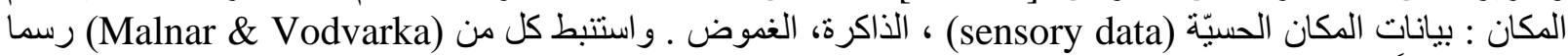

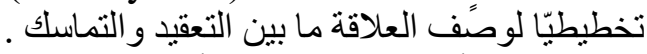

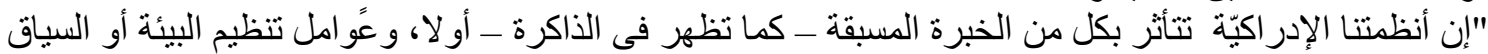

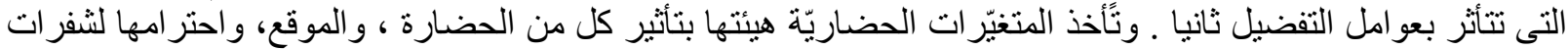

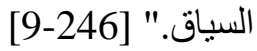

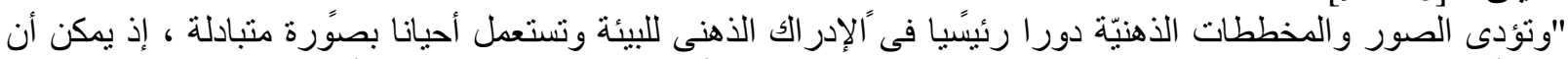

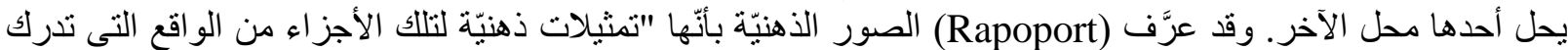

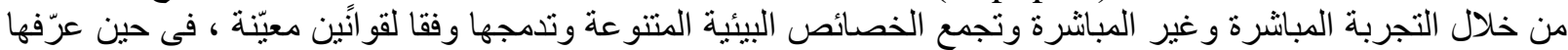
(Bronzaft et al)

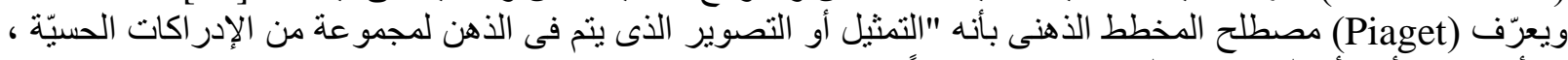

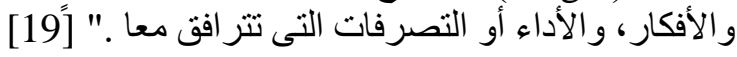

\section{7. البعد الإدراكى للتصميم}

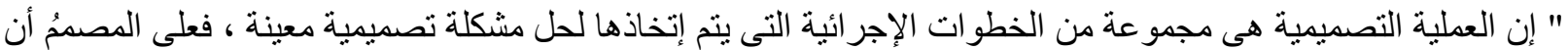

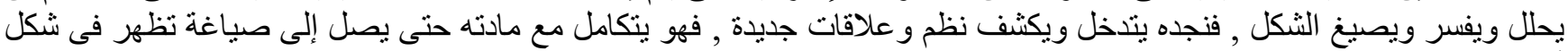

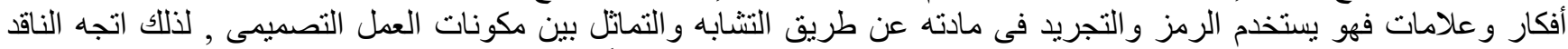

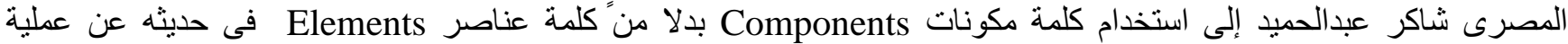
الإدر الك , وذلك لأن المكونات تعنى التفاعل أما العناصر فتعنى التجزئة و الانفصال عن الموضوع المدركُ . ." [2] 


\section{SJFA Scientific Journal of the Faculty of Fine Arts Alexandria University}

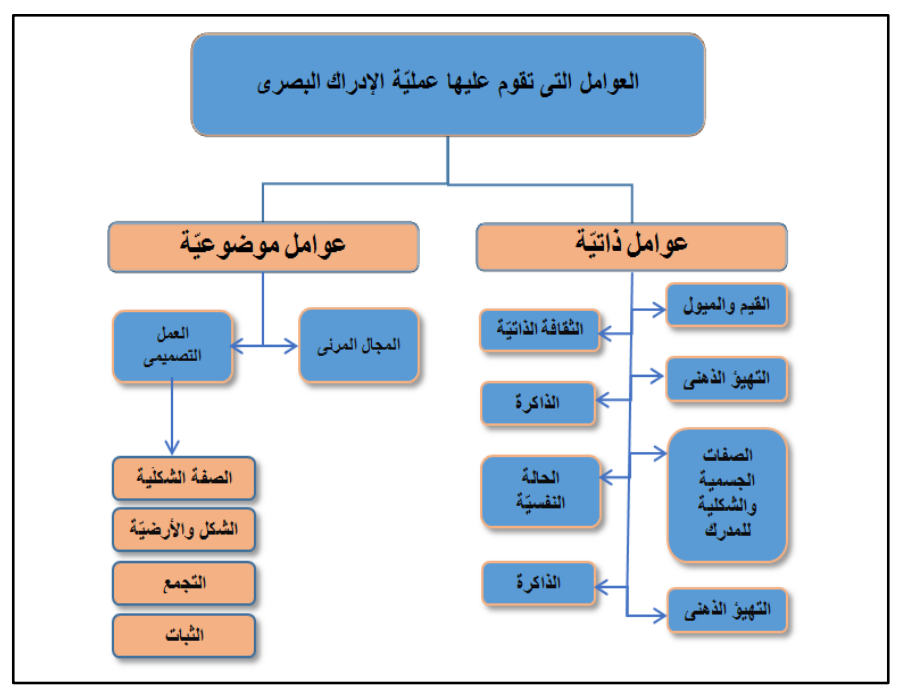

شكل ا : رسم توضيحي يبين العو امل التى تقوم عليها عمليّة الإدر الك البصرى

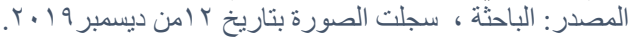

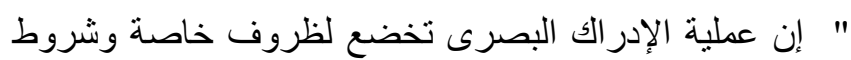

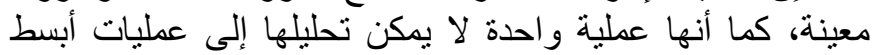

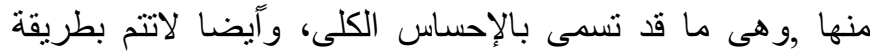

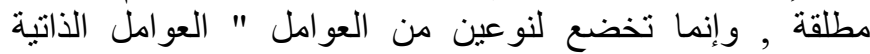

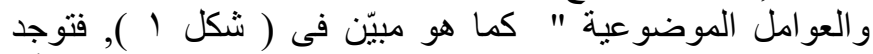

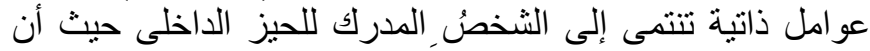

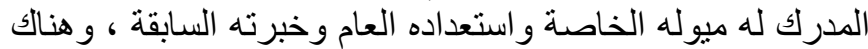

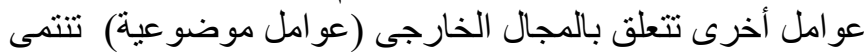

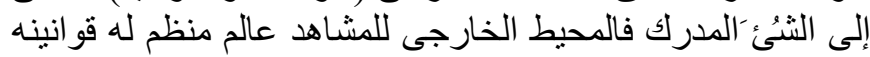

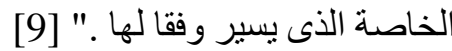

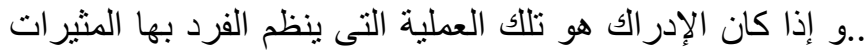

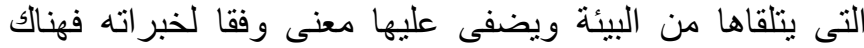

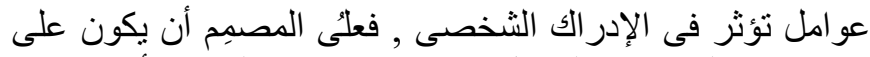

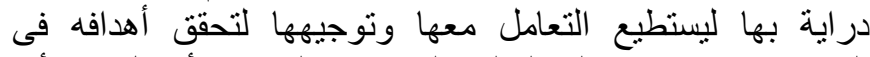

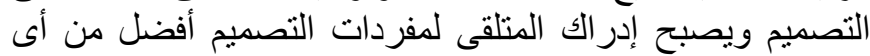
وقت مضى .

\section{V. الإنطباعات المختلفة للحيّز ات الداخليّة}

: visual effect الإنطباع البصرى 1, V

" يستمتع المُستخِدم بالحيز الداخلى عندما يكون واضحاً ومتجانساً أمام عينيه وعندئذ يحدث لديه إدراك لصورته البصرية, وقد يتكوّن

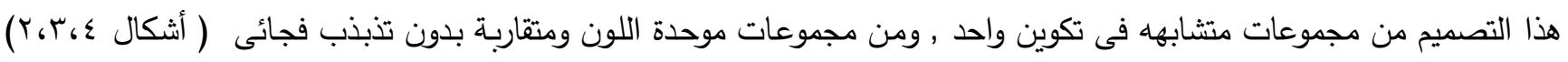

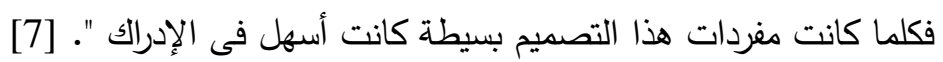

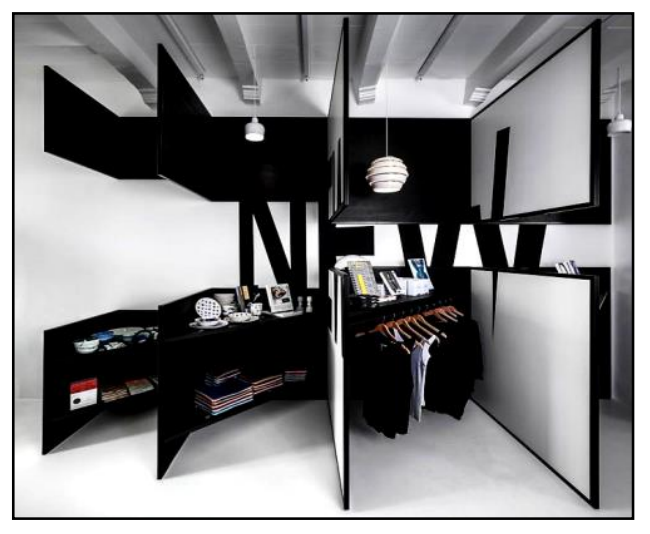

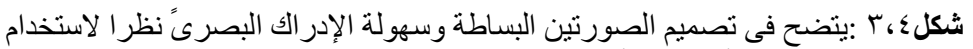

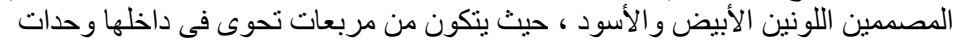

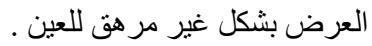

http://fastcodesign.tumblr.com/post/103150346702/this-shop-is-a- : المصدر .walk-in-optical-illusion-i29

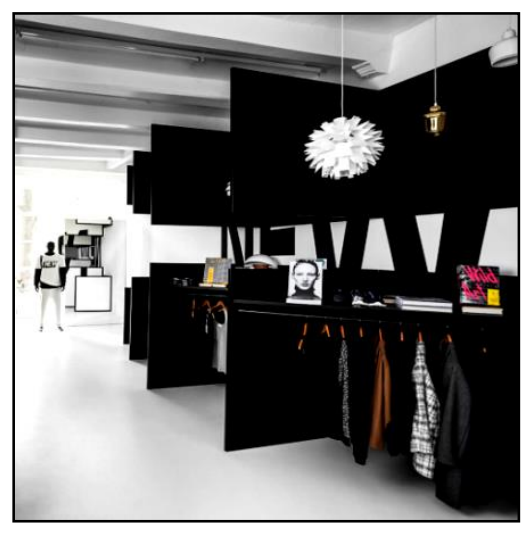

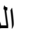
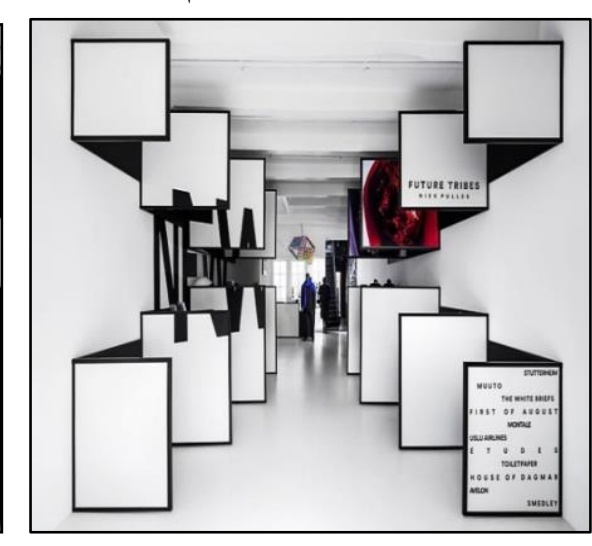

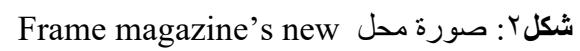
I29 من تصميم معمارى مكتب Amsterdam shop

المصدر:

http://fastcodesign.tumblr.com/post/103150346702/t .his-shop-is-a-walk-in-optical-illusion-i29

\section{: Ideological effect الإنطباع الفكرى r,}

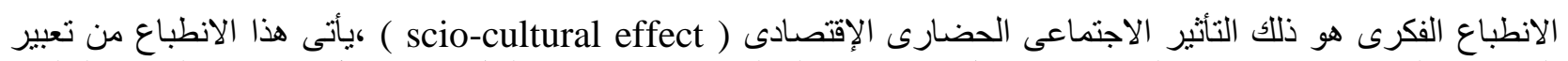

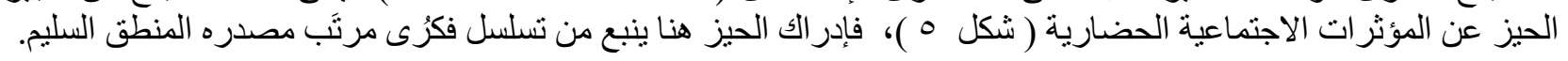


Z. L. Abd Elhakeem, Mental Perception of Visual Image in Designing Contemporary Interior Spaces ; Vol. 8, R. 2020, Issue No. 1.

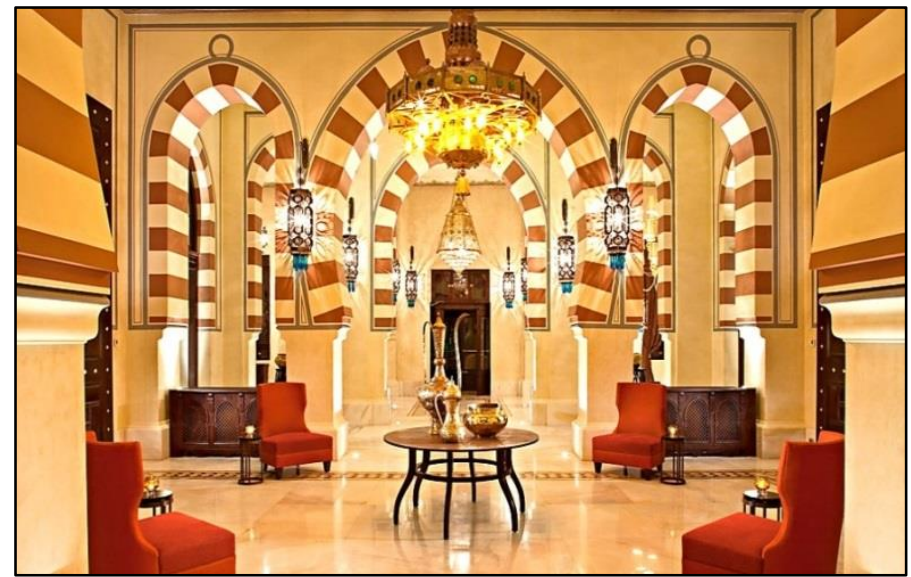

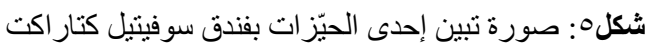

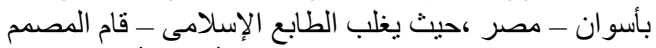

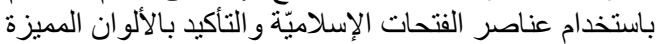

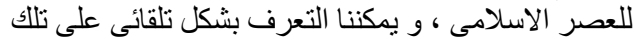
الحضارة المؤثرة بمجرد النظر إلى الحيّز

المصدر:

http://motivationmagazin.eu/2011/11/01/sofitellegend-old-cataract-aswan-hotel-endlichrenoviert/\#jp-carousel-1659

\section{: Emotional effect الإنطباع العاطقى, r,V}

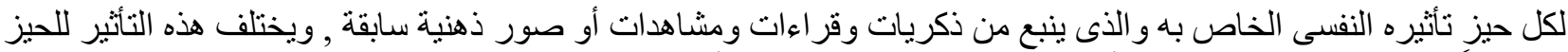

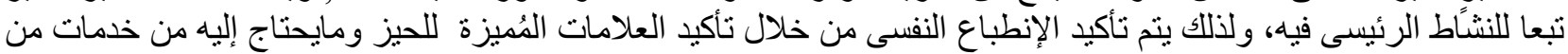

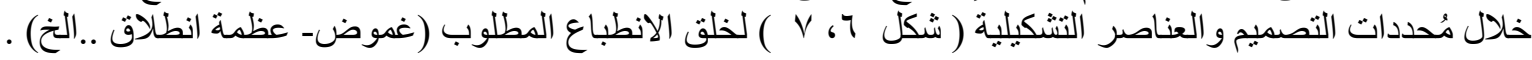

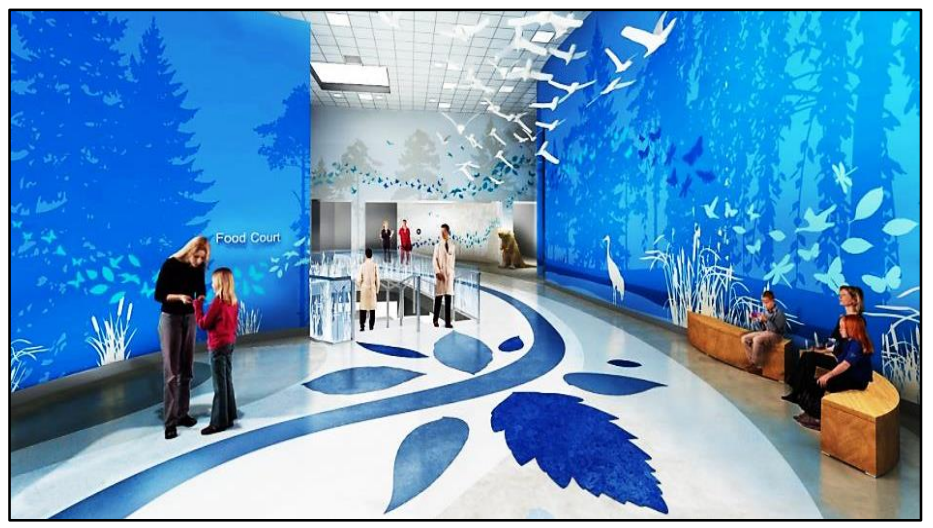

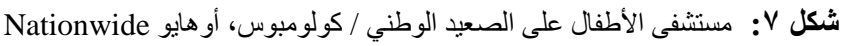

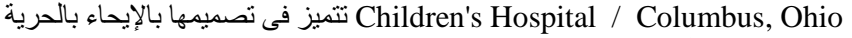

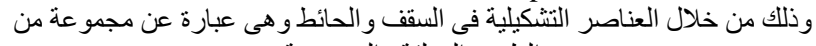

$$
\text { الطيور المعلقة والمرسومة المبن }
$$$$
\text { المصدر: }
$$

https://www.pinterest.com/pin/499969996105183817/?lp=true

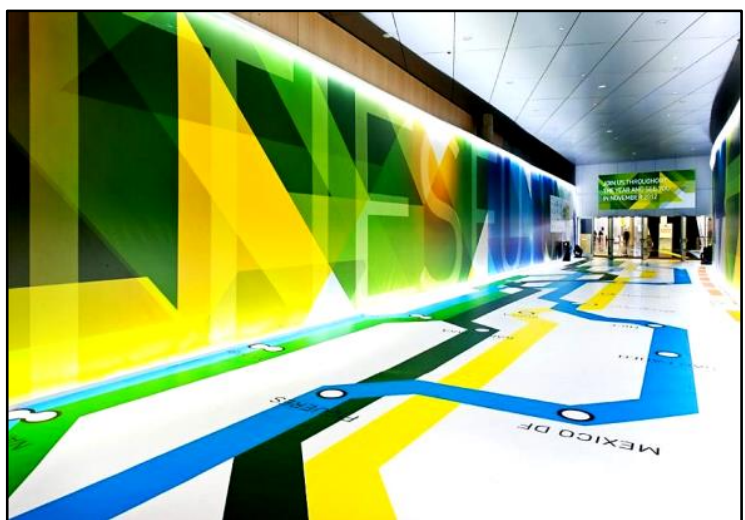

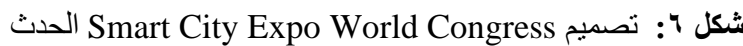

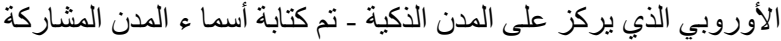

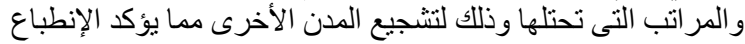
النفسى لتللك المدن بالإنطلاق

المصدر: /http://vertigographix.com/Projects/smart-city-congress

\section{: Spiritual effect الإنطباع الروحانى, V}

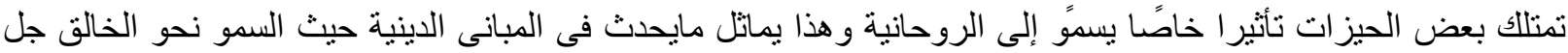

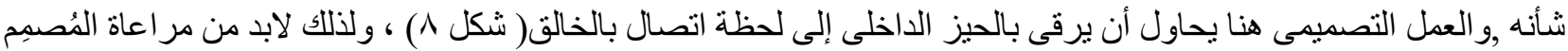

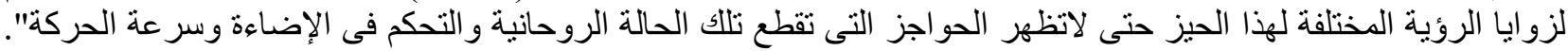




\section{SJFA}

Scientific Journal of the Faculty of Fine Arts Alexandria University

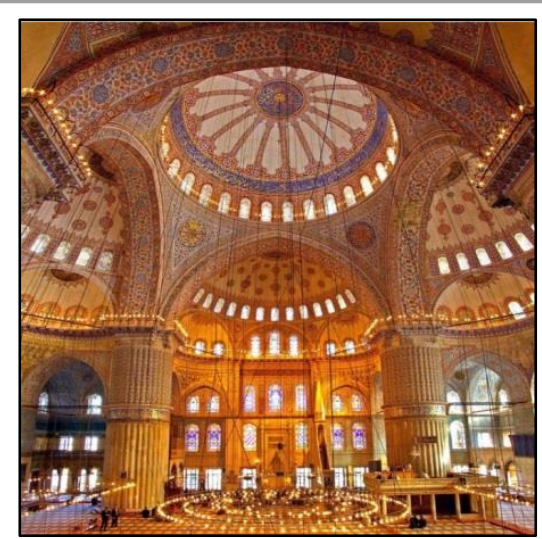

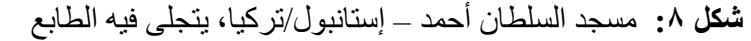

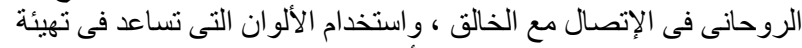
هذه الأجو اء.

https://www.trekearth.com/gallery/Middle_East/Turkey/Marma $\mathrm{ra} / \mathrm{Istanbul} / \mathrm{Sultanahmet/photo170801.htm}$

\section{: Psychological effect الإنطباع النفسى ( •,V}

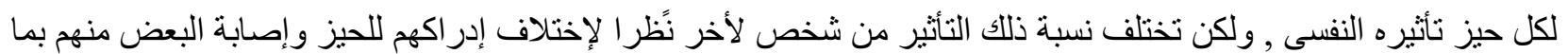

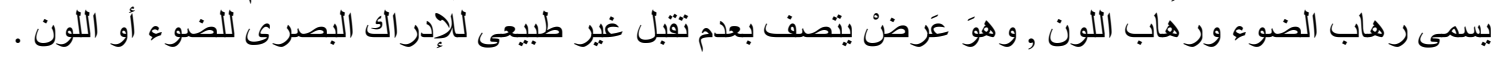

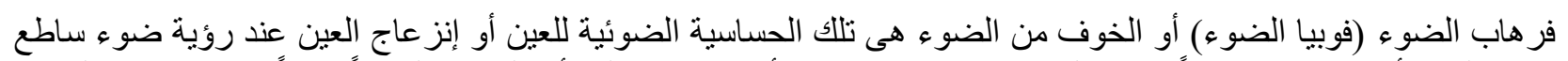

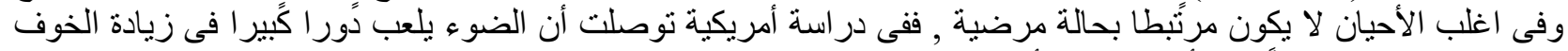

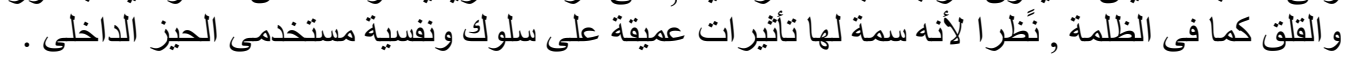

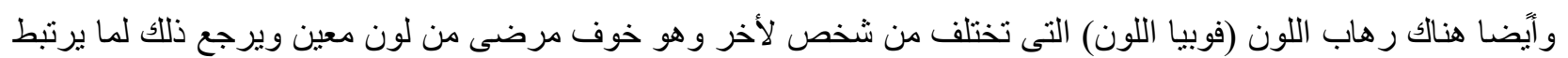

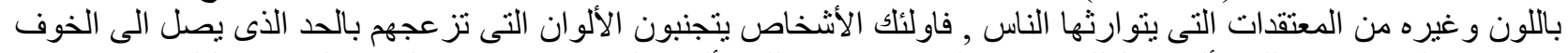

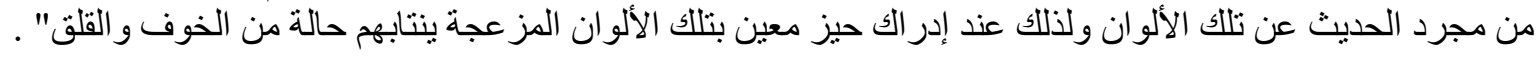

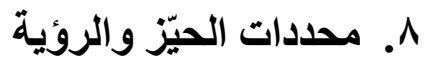

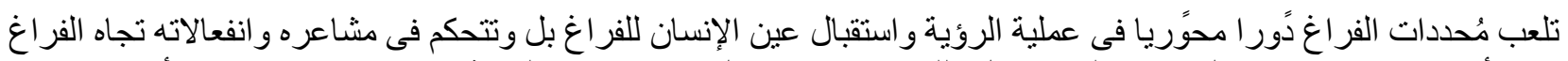

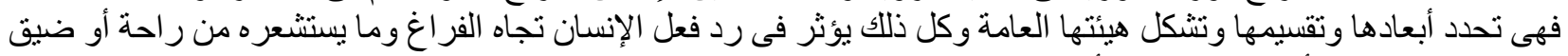

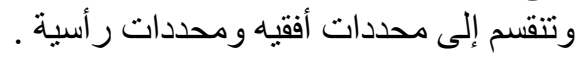

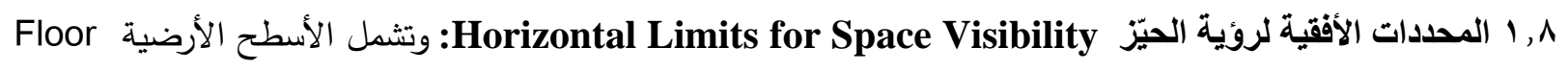

Overhead Planes والأسطح الأفقية Planes

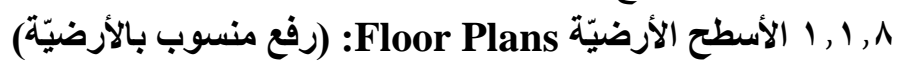

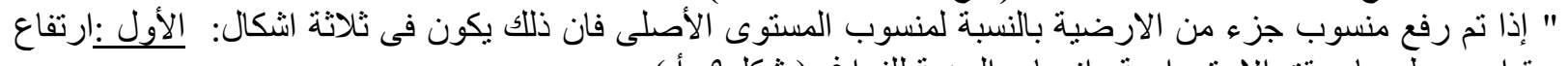

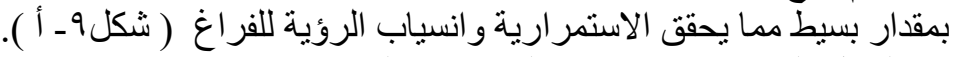

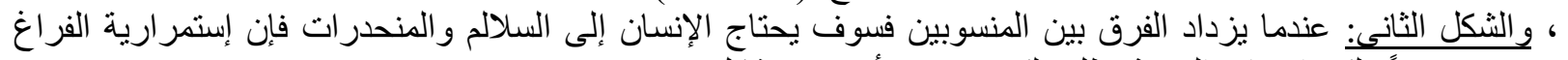

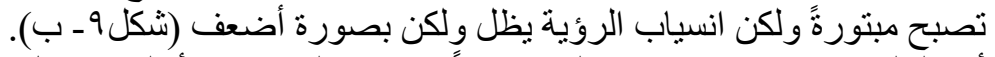

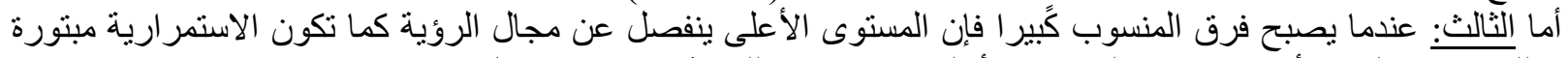

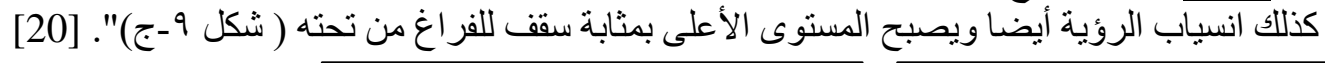
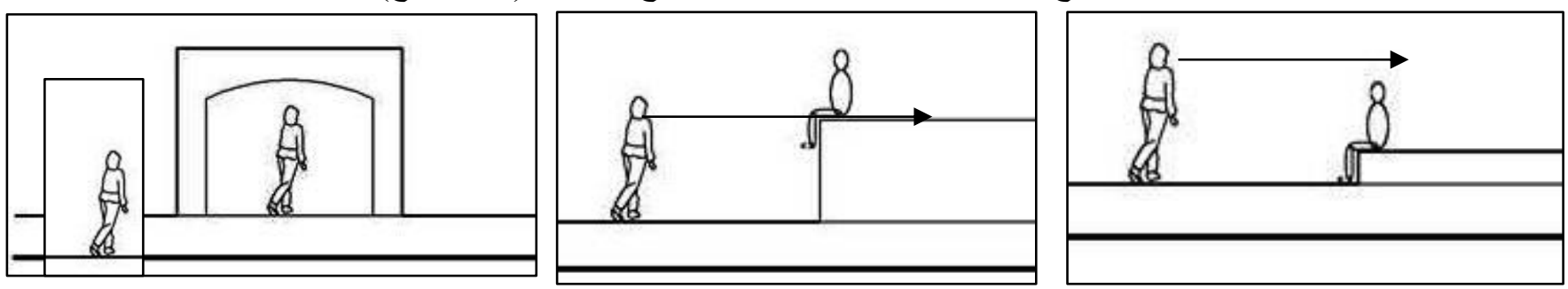

شكل 9: (أ) ، (ب) ، (ج) يوضح العلاقة بين منسوب الأرضّ وقوة الإتصال البصرى و انسياب الرؤية بين الحيزات

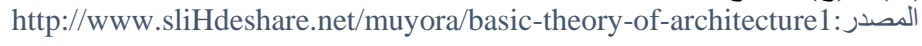


Z. L. Abd Elhakeem, Mental Perception of Visual Image in Designing Contemporary Interior Spaces ;

Vol. 8, R. 2020, Issue No. 1.

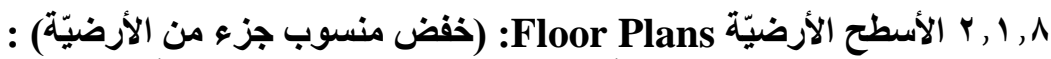

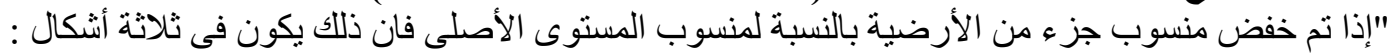

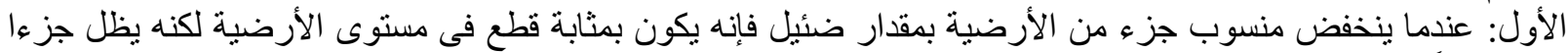

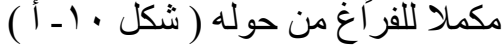

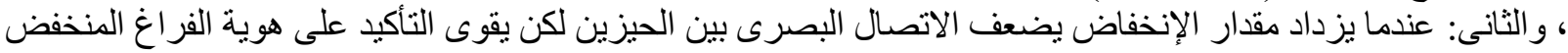

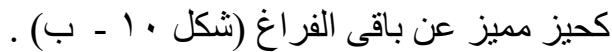

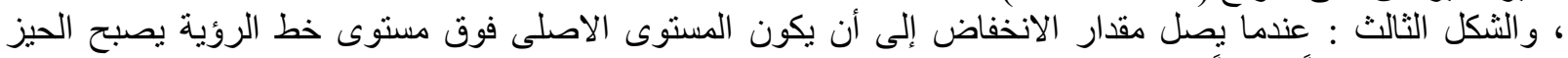

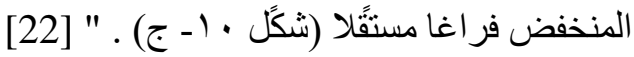

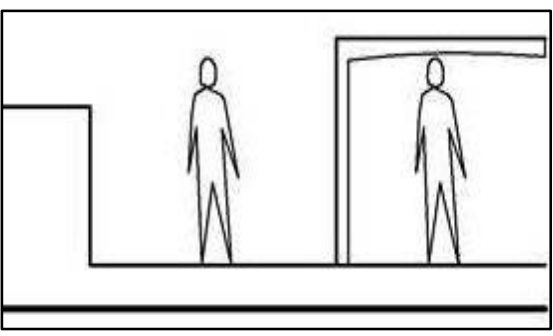

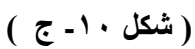

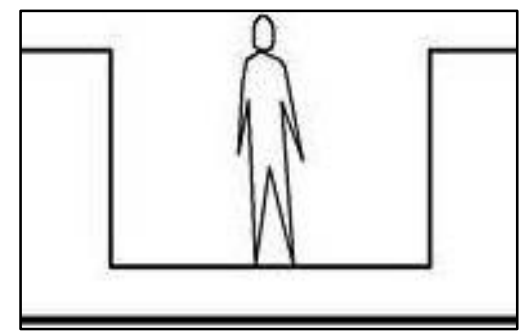

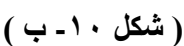

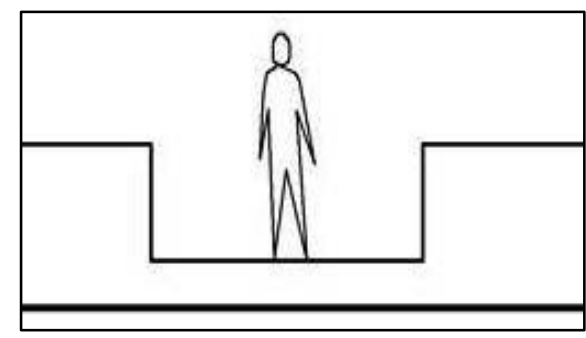

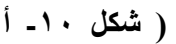

شكل · ا: المكون من (أ) ، (ب) ، (ج) يوضح العلاقة بين منسوب الأرض وقوة الإتصال البصرى وانسياب الرؤية بين الحيزات

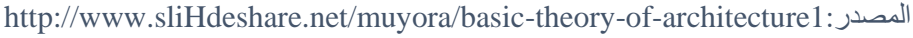

: Ceiling الأسقف

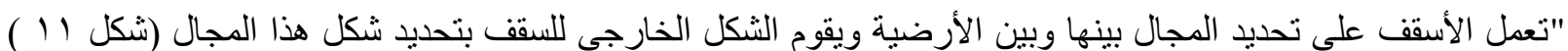

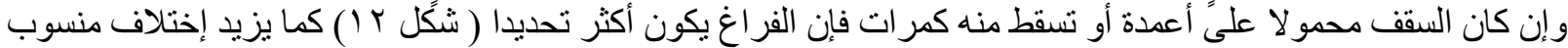

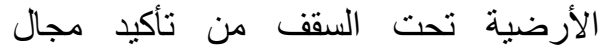
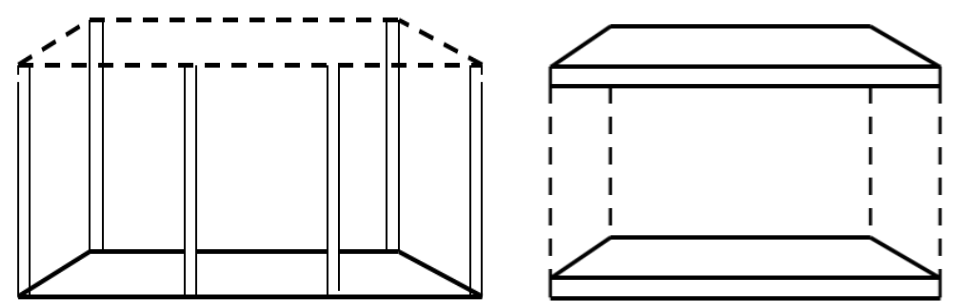

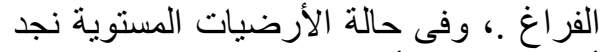

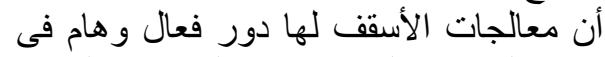

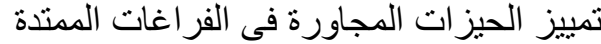

(11] شكل سا (1)."

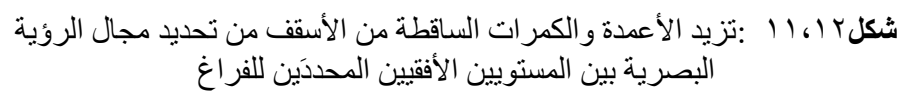

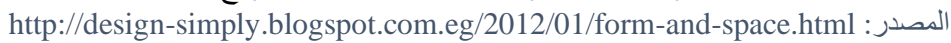

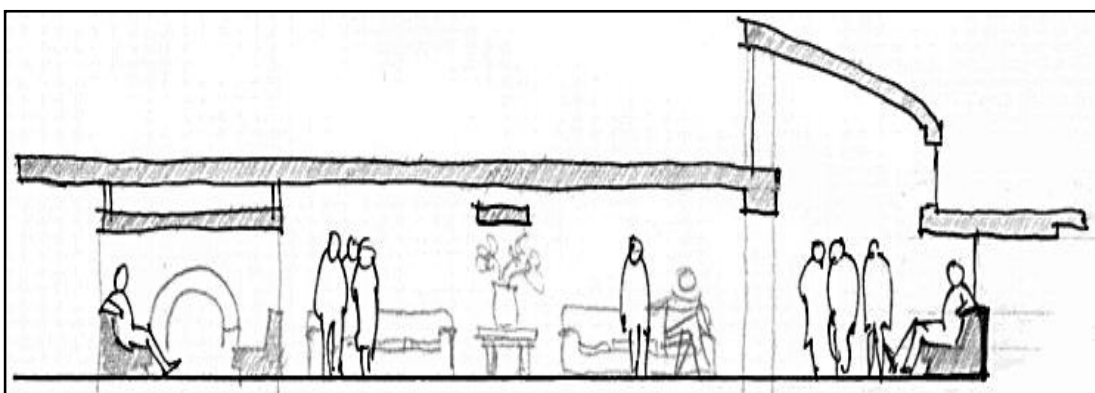

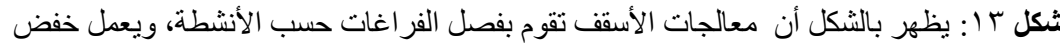

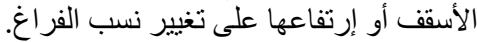

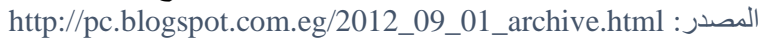




\section{SJFA}
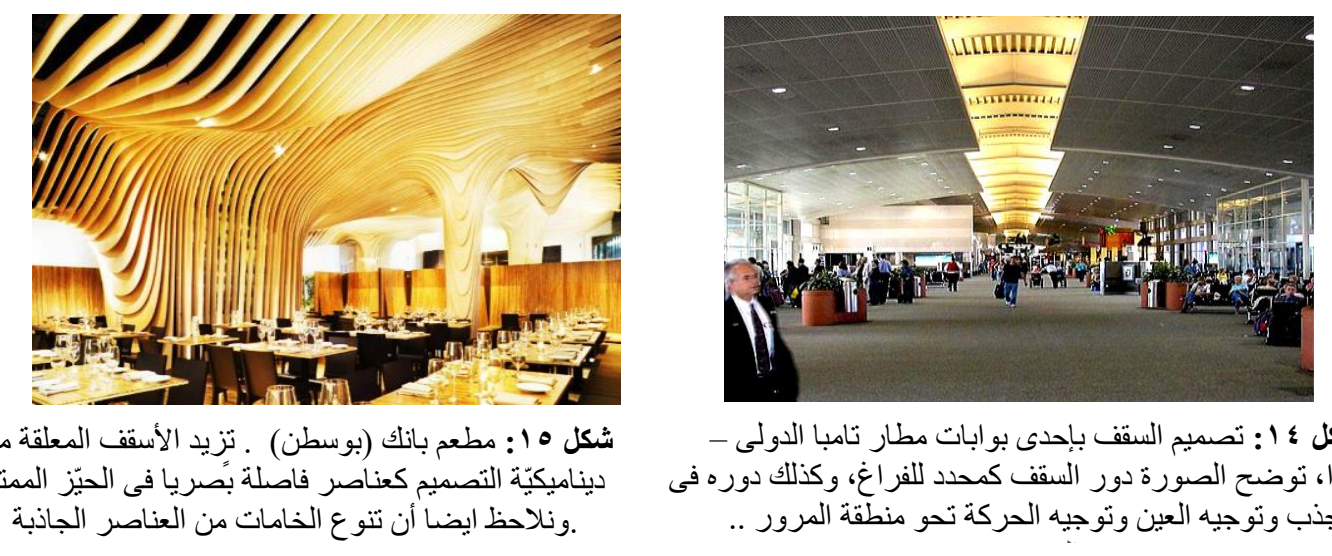

شكل \& 1 : تصميم السقف بإحدى بوابات مطار تامبا الدولى -

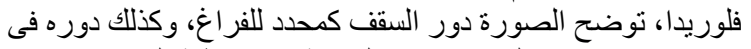

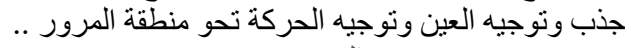

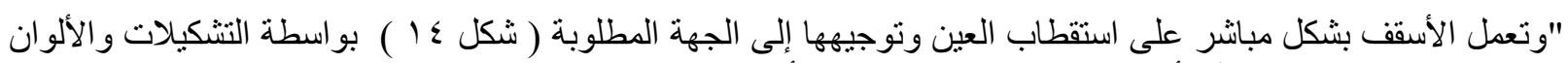

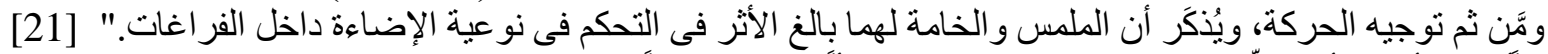

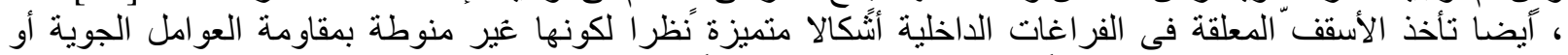

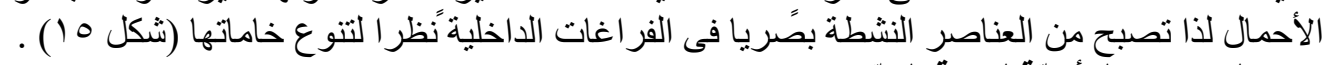

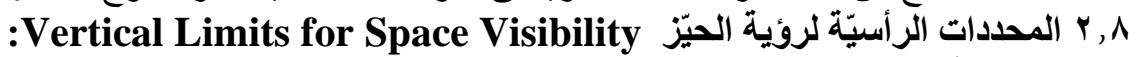

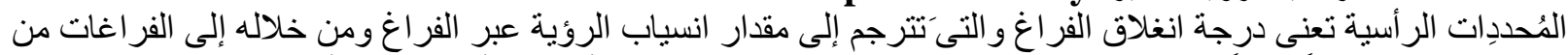

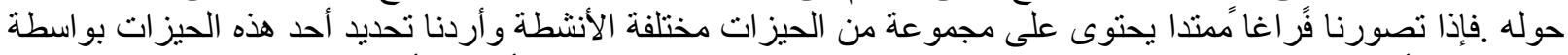

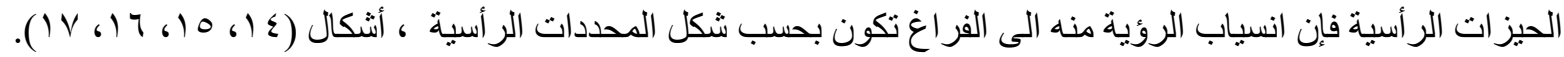

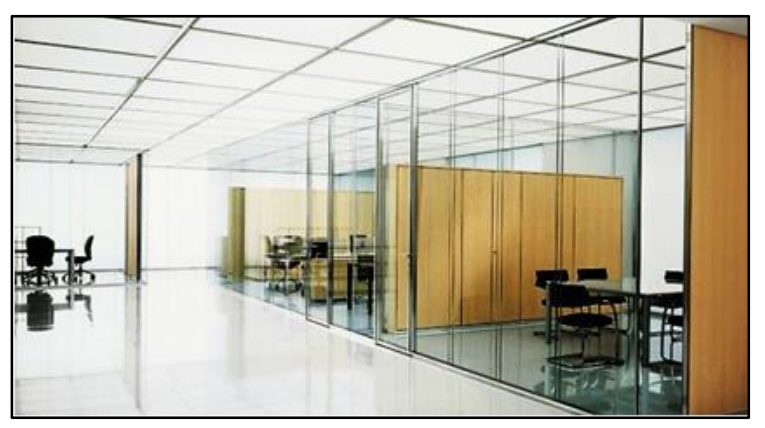

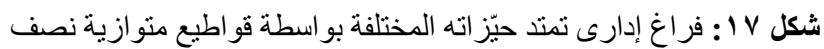
شفافة تضفى بعض الخصو إدى تصنية على الحئ الديز ات ولكنها تسمح بانسياب الرؤية عبر الجهات المختلفة علئ

https://www.google.com.eg/search?q=Parallel+Planes\& : المصند الجهر

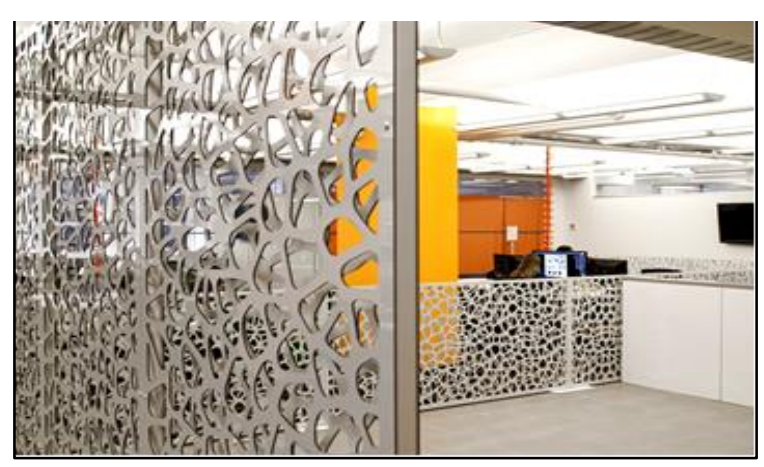

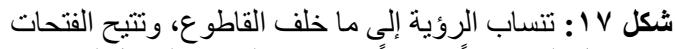

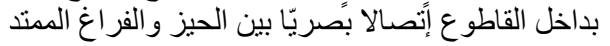

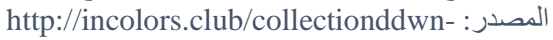

decorative-partition-wall.htm

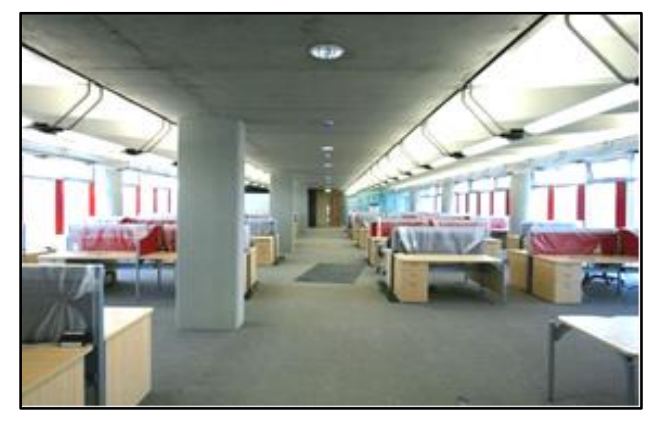

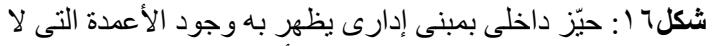

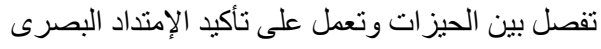
http://www.building.co.uk/elm-parkdublin/3109414.article\#

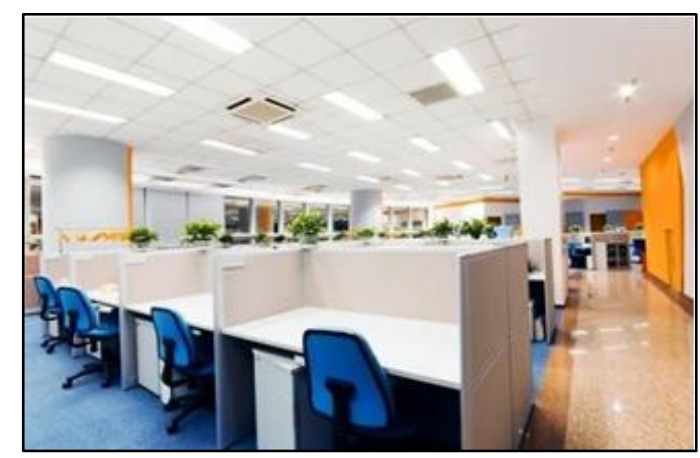

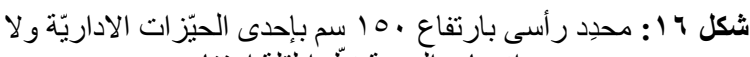

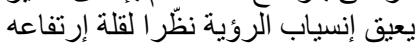

http://www.hyperdecoration.com/?page_id=1751 المصدر: 


\section{9. الدراسات و النماذج التحليلية}

شهح القرن العشرين وما بعدها العديد من التصميمات الداخلية التى تغيرت معها شكل المعالجات البصرية لمحددات ومفردات

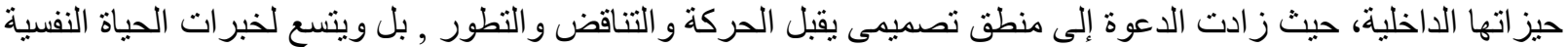
والإجنماعية . و من هذه النماذج :

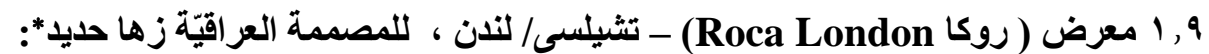

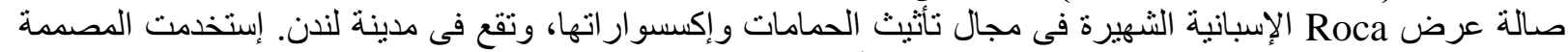

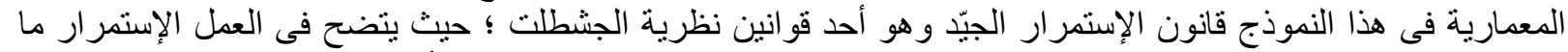

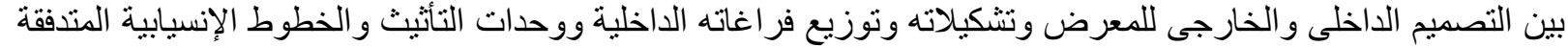

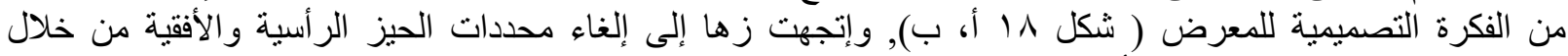
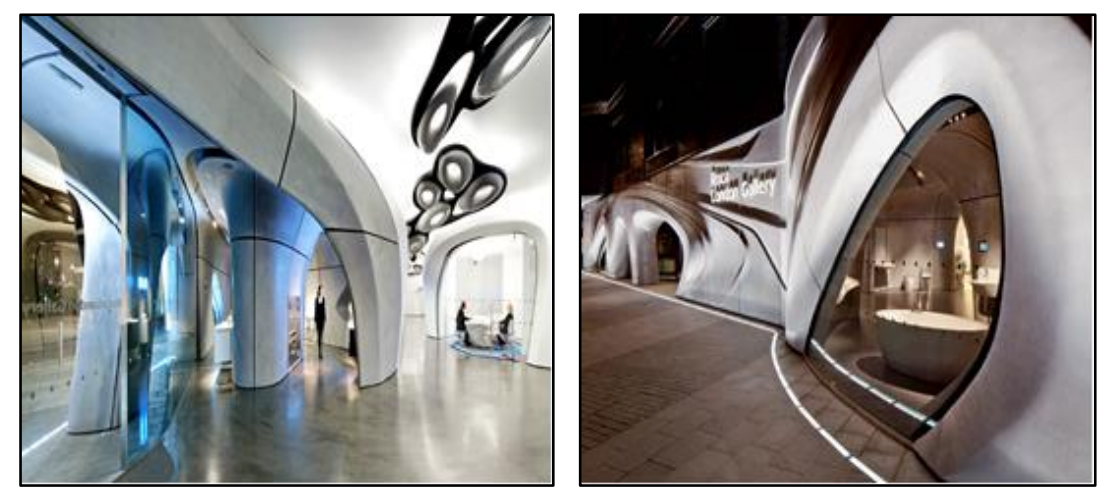

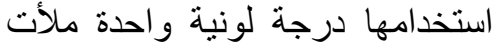

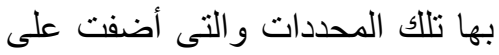
الحيز الكثير من الإنسيابية وجذب الإنب للحركة عند منطقة الإستقبال مع الإنة الإنيز

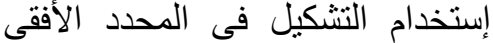
العلوى والذى ساهم من زيادة تأكيد هذا المدخل بالإضاءة المسلطة المنة عليه

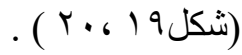

شكل 1/ إ: المكون من (أ) ، (ب) يبين التصميم الداخلى والخارجى لمعرض روكا ويظهر فيه

حالة الإستمر ار الجيد و الدمج بين المساحات الداخلية والخارجية بحيث لا يمكن الفصل بينها
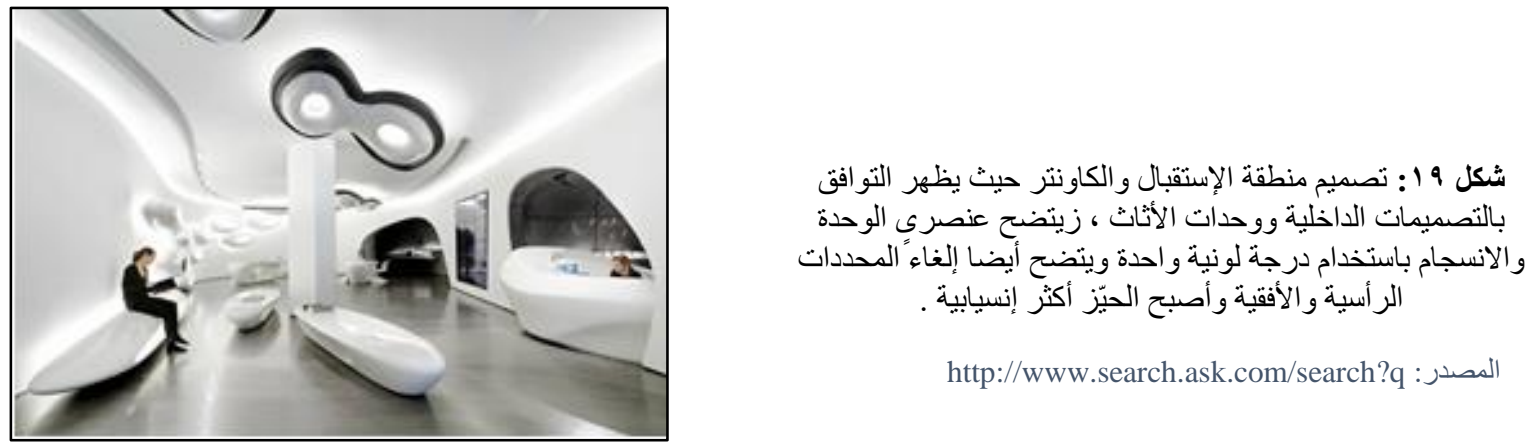

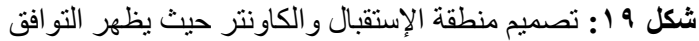

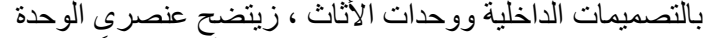

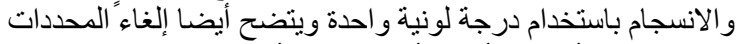
الرأسية والأفقية وأصبح الحيّز أكثر إنسيابية . http://www.search.ask.com/search?q : المصدر

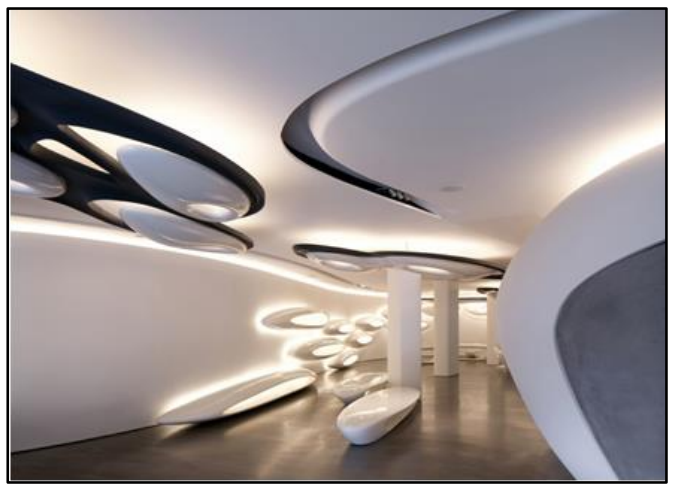

شكل • r : إستخدام اللون الأسود فى السقف مع الأنابيب الضوئية لتأكيد

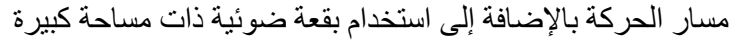

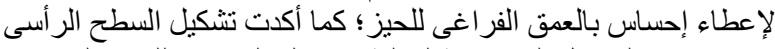

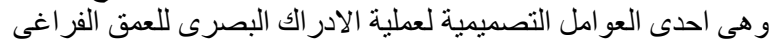

http://interiii.com/2013/09/roca-london-gallery-by- : المصدر zaha-hadid-architects/roca-london-gallery-by-zaha-hadidarchitects- 03

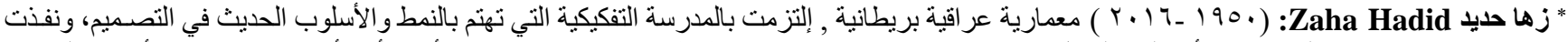

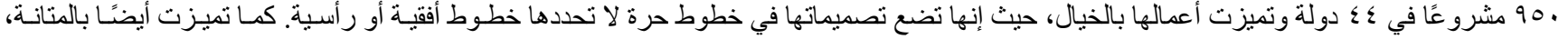




\section{SJFA}

Scientific Journal of the Faculty of Fine Arts Alexandria University

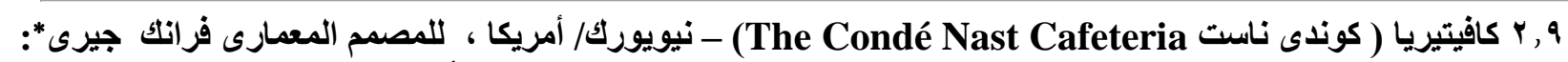

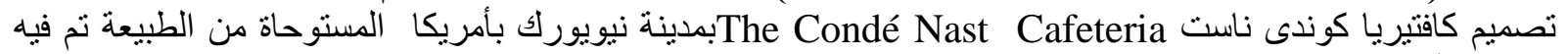

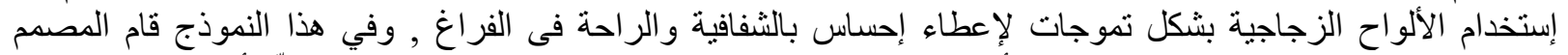

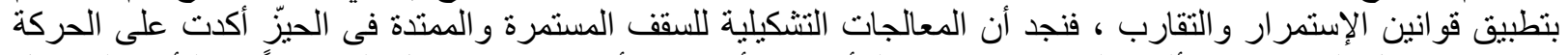

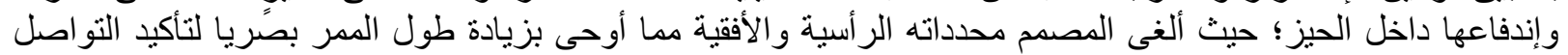

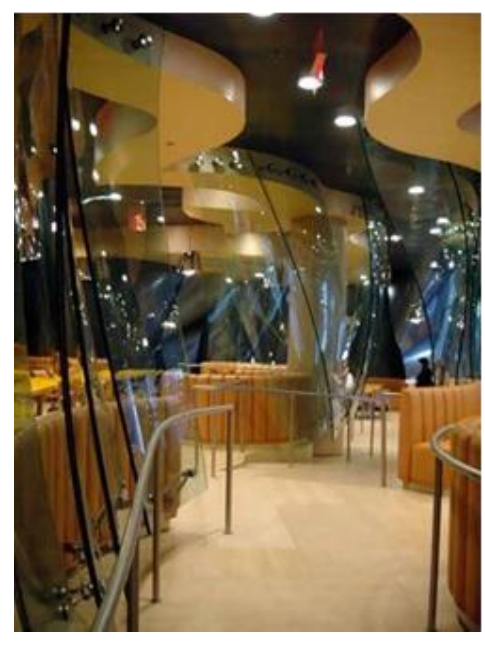

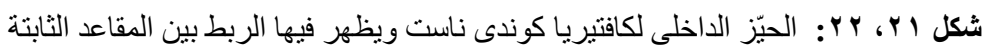

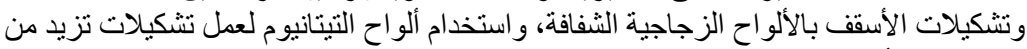

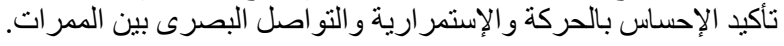

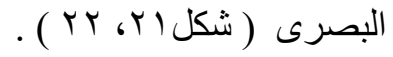

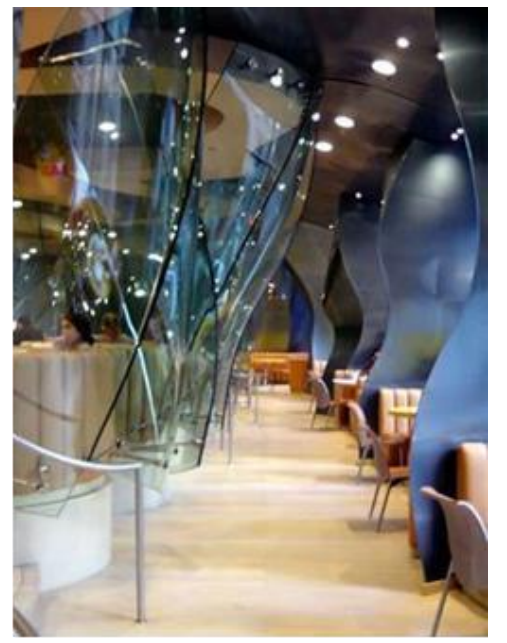

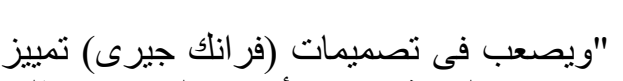

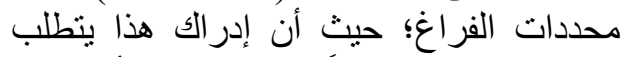

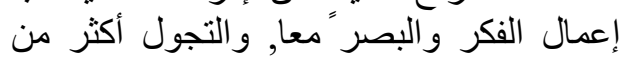

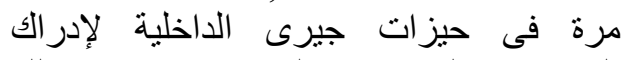

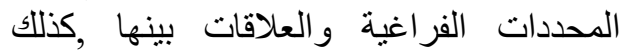
الدوران حول المبنى ورؤيته من زوايا عديدة

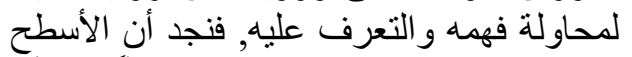

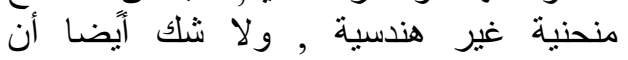
الإحساس داخل حيزات جيرى إحساس مثير وجذاب , و هو مايمكن ان يلبى رغبة المشاهد

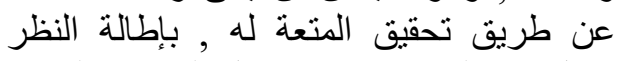

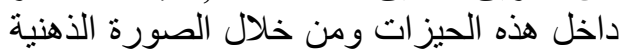
المتغيرة بإستمرار وإن وعمل تشكيلات لونية وزخرفية بصرية". [11]

q, ج مجمع عيادات أسنان (Dental Clinic Ku64) - برلين/ ألمانيا ، للمصمم المعمارى جرافت Graft)

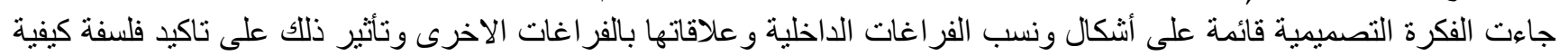

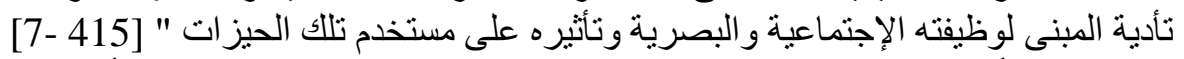

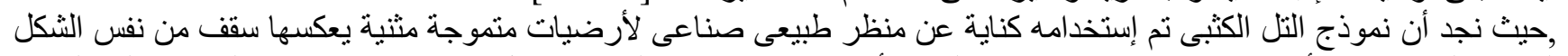

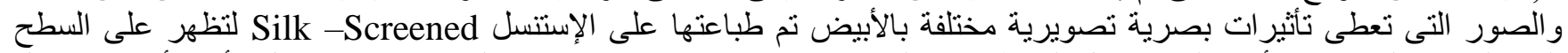

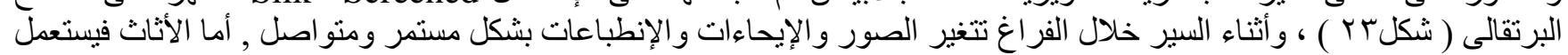

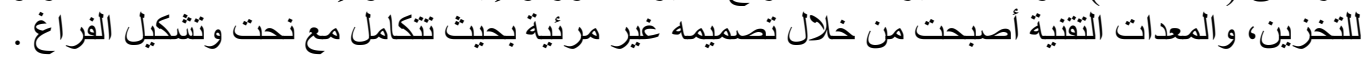

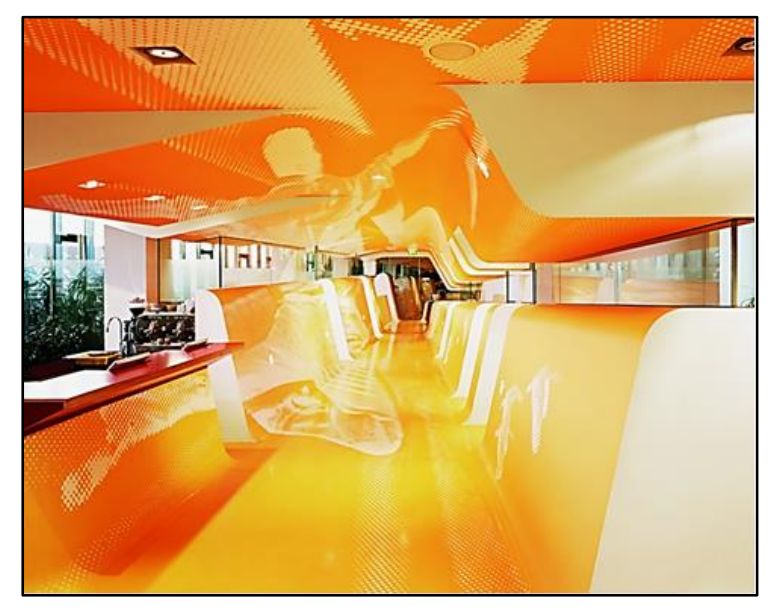

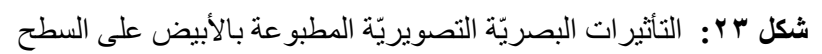

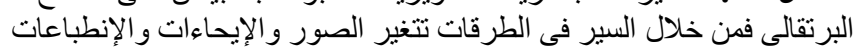

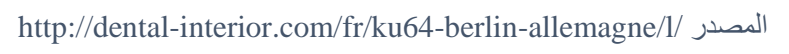

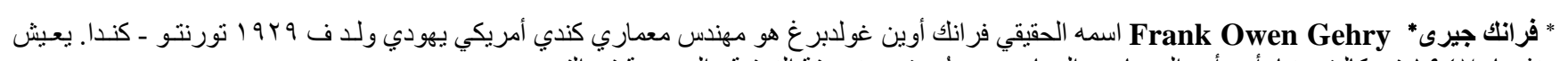

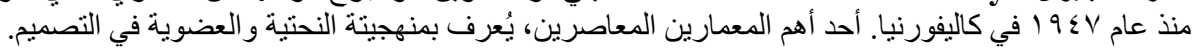


Z. L. Abd Elhakeem, Mental Perception of Visual Image in Designing Contemporary Interior Spaces ;

Vol. 8, R. 2020, Issue No. 1.

ـ إن المسطحات الأفقية تنقلب وتتحول إلى حوائط ومابينهما رواق وسطى مثل الوادى ومجمو عة من الأبواب الزجاجية تقطع ذللك

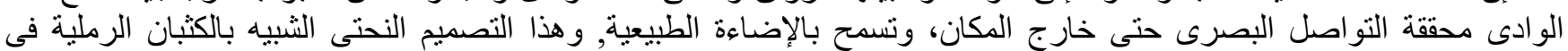

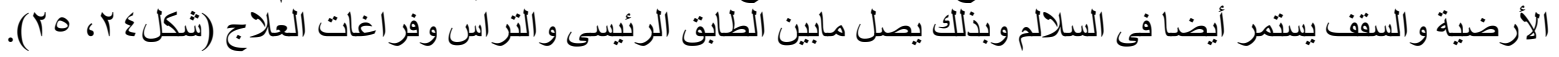

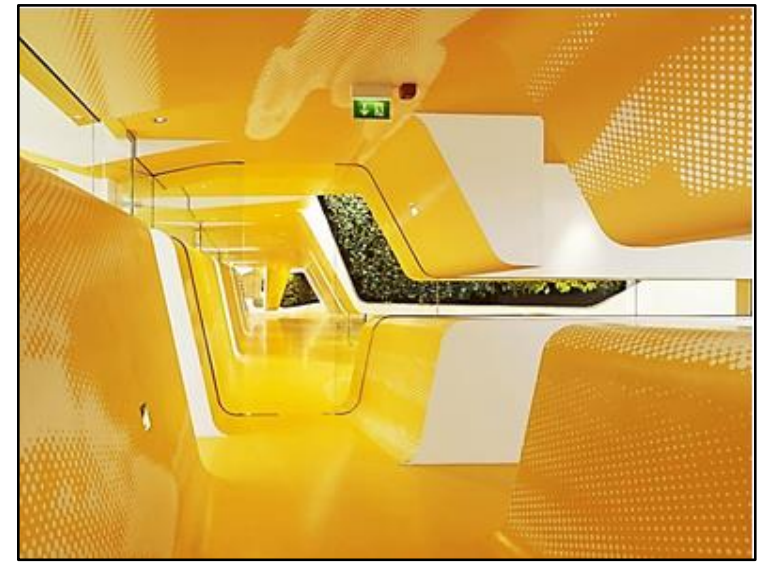

شكل ه r : التأثير ات البصرية فى تصميم الحوائط و الأسقف و علاقتهما بالممر

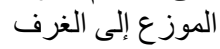

http://dental-interior.com/fr/ku64-berlin-allemagne/المصدر

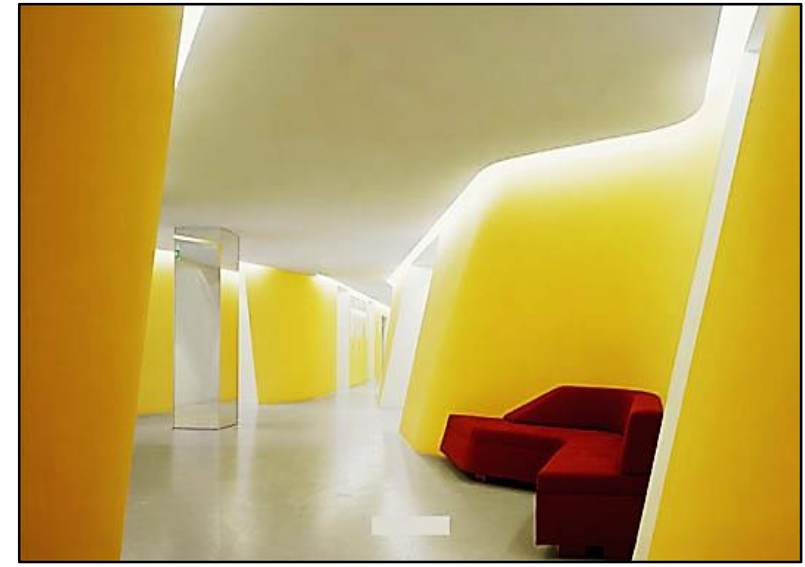

شكل ؟ ؟ : تحقيق التو اصل البصرى فى التصميم الداخلى لمنطقة الإسنقبال وممر التوزيع بالدور الأول فئرل

http://kurrel.blogspot.com.eg/2009/10/ku64-dental-clinic-

ويذلك يستطيع المصمم تنظيم الاتتقال البصري ضمن سياق الهدف الذي ينشده في الفراغ الداخلي ، كما يستطيع التحكم بتسلسل

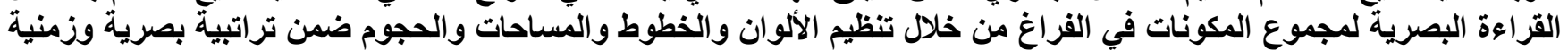

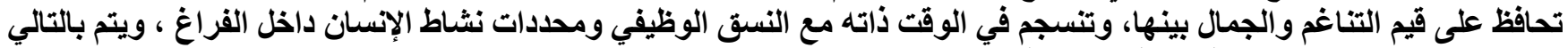

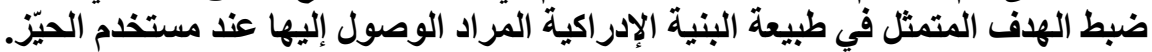

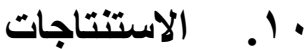

يعتمد الإدر الك الذهنى للصورة البصرية على شكل الحيّز الفر اغى و عناصره، وكذلك قدرة الإنسان نفسه على الإدر الك وهى تختلف

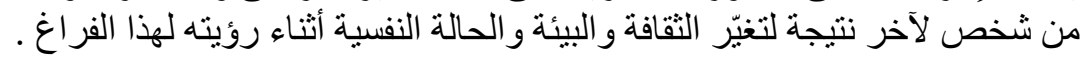

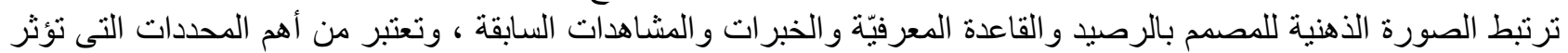

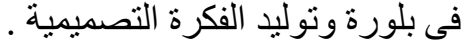
الإدر الك البصرى له دوليد دور فى تتكيل وتصميم الحيزات الداخلية حيث يقوم فن تشكيل الأسطح و الكتل إلى خلق فر اغات تحقق إنتفاعا ومتعة فنية . تلعب مُحددات الفراغ الأفقية والرأسية دورا محَّريا فى" عملية الرؤية واستقبال عين الإنسان للفر اغ بل وتتحكم فى مشاعره • يسنطيع المصمم تنظيم الإنتقال البصرى ضدمن سياق الهدف الذى ينشده فى الفراغ الداخلى.

يوصى البحث أنَّ تصميم الحيز ات الداخليّة يحتاج إلى أكثر من مُجرد در اسة نظرية؛؛ بل يحتاج إلى محمو عة من الدر اسات التهات التكاملية

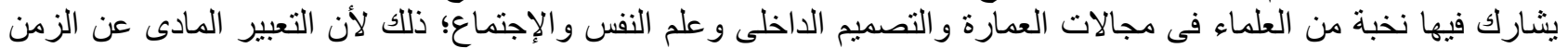

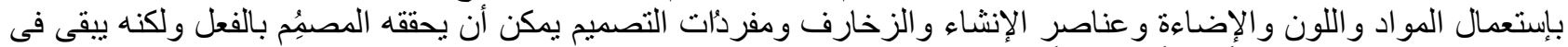

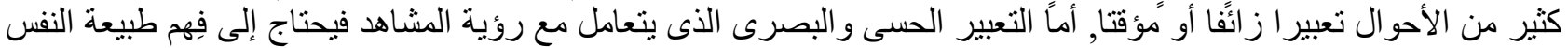

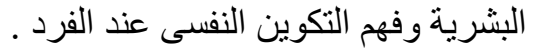




\section{SJFA Scientific Journal of the Faculty of Fine Arts Alexandria University}

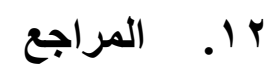

ا . الحارث عبد الحميد حسن، اللغة السيكولوجية فى العمارة، المدخل إلى علم النفس المعمارى، دار صفخات للدراسات والنشر،

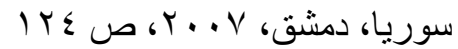

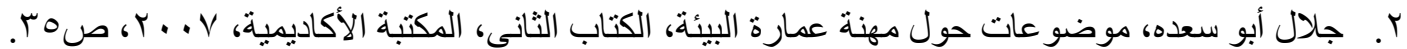

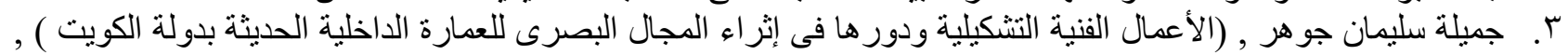

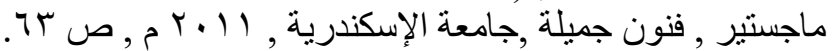
ع. رضا شحاتة أبو المجد , تأثثير جدلية الضوء واءئلة والنور على إنبثاق المهنى الروحانى فى الحيز الهندسى,المقالة الرابعة ,فبر اير $r \cdot 11$

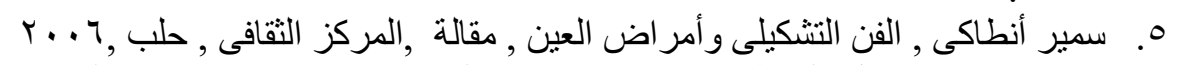

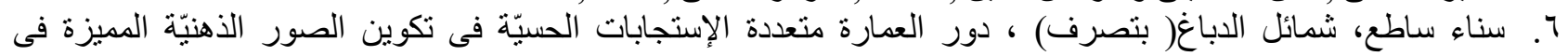

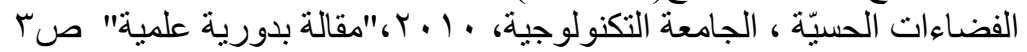

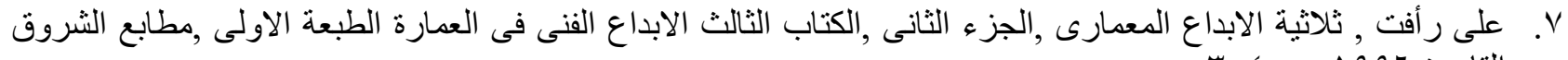

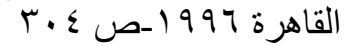

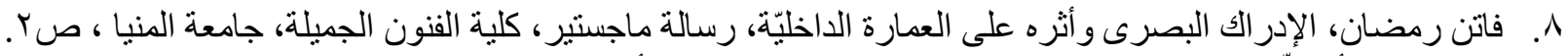

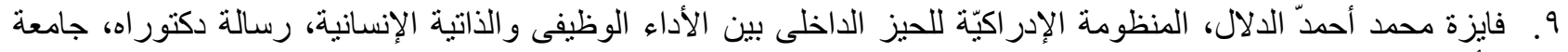

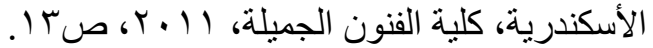

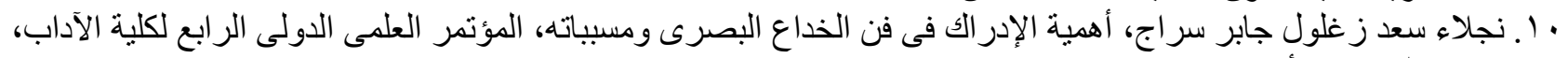

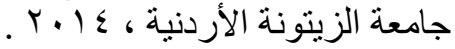

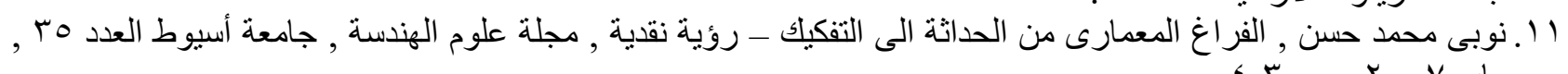

12. Hall ,Edward T., .Beyond Culture., (Garden City,N. Y.: Anchor Press/ Doubleday) New York,1977.,(p.177)

13. Rapoport ,Amos , .Human Aspects of Urban Form, Towards a man. environment approach to urban form and Design., Paragon press, Ltd. , Heading ton Hill Hall , Oxford, England ,1977.(p.186).

14. Richard D Wright. Visual Attention. Oxford University Press.New York 1998.p26

15. Passini, R. Wayfinding in Architecture. Van Nostrand Reinhold Company, New York, 1992., (p. 47)

16. Pearson Education Australia; 2002.

17. Yarbus, Alfred L., Eye Movements and Vision. (New York: Plenum Press), 1967. (p.211)

18. Malnar, Joy Monice, and Vodvarka, Frank, .The Interior Dimension., A Theoretical Approach to Enclosed space, Van Nostrand Reinhold Company, New York, 1992.

19. http://www.jouhina.com/article.php?id=4078

20. http://www.learningandteaching.info/learning/piaget.htm

21. http://www.slideshare.net/muyora/basic-theory-of-architecture

22. https://commons.wikimedia.org/wiki/File:Tampa-international-airport-interior.jpg

23. https://rinbo.files.wordpress.com/2011/05/form-space.pdf 
الاورية العلمية لكلية الفنون الجميلة ـ جامعة الإسكندرية

SJFA

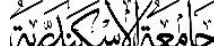

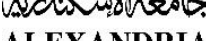
ALEXANDRIA

\title{
Mental Perception of the Visual Image in Designing Contemporary Interior Spaces
}

\author{
Z. L. ABD ELHAKEEM ${ }^{3}$
}

\section{ABSTRACT}

Interior architecture is a unique expertise that combines technical and aesthetic solutions within the framework of a goal that organizes all those solutions, and in a cognitive environment that can communicate and declaim human senses and their levels of perception; a designer is the one who takes design issues in architecture spaces, and he must be aware of this goal and works to raise the level of compatibility between space, human and the environment, i.e., a design should meet the human requirements and functional needs; sensory and psychological, and works to control that goal by taking advantage of all scientific developments and studies and their developments in design.

Visual image sketch the cognitive space that a person occupies, thus visual communication process has the specific and leading role in translating the contents of the space, and this process is based on the visualized image of the place and the mental images or impression generated by the total of those images; So we may call it the perceived image, and this process is related to the physiological basics and procedures that arise from the ability of the human sense of vision to respond to specific interval and values of images and colors, and to the ability of the human mind to translate and interpret those images.

This study aims to identify the effects through which perception and comprehension are achieved to adopt it as a design determinant during the design idea-making process. It is also an attempt to find indicators of internal spaces with a clear and distinctive mental image that is easy to retrieve by exploring the main procedure for designing these spaces.

\footnotetext{
${ }^{3}$ Faculty of fine Arts El Minia University zeinab.khalaf@mu.edu.eg zeinab10041@yahoo.com
} 